\title{
The use of a tablet-based app for investigating the influence of autistic and ADHD traits on performance in a complex drawing task
}

\author{
S. Savickaite ${ }^{1} \cdot$ C. Morrison ${ }^{1} \cdot$ E. Lux ${ }^{2} \cdot$ J. Delafield-Butt $^{2} \cdot$ D. R. Simmons ${ }^{1}$
}

Accepted: 8 November 2021 / Published online: 11 January 2022

(c) The Author(s) 2021

\begin{abstract}
This paper describes a smart tablet-based drawing app to digitally record participants' engagement with the Rey-Osterrieth complex figure (ROCF) task, a well-characterised perceptual memory task that assesses local and global memory. Digitisation of the tasks allows for improved ecological validity, especially in children attracted to tablet devices. Further, digital translation of the tasks affords new measures, including accuracy and computation of the fine motor control kinematics employed to carry out the drawing Here, we report a feasibility study to test the relationship between two neurodevelopmental conditions: autism spectrum disorder (ASD) and attention-deficit/hyperactivity disorder (ADHD). The smart tablet app was employed with 39 adult participants (18-35) characterised for autistic and ADHD traits, and scored using the ROCF perceptual and organisational scoring systems. Trait scores and conditions were predictor variables in linear regression models. Positive correlations were found between the attention-to-detail, attention-switching and communication subscales of the autistic trait questionnaire and organisational scores on the ROCF task. These findings suggest that autistic traits might be linked to differential performance on the ROCF task. Novelty and future applications of the app are discussed.
\end{abstract}

Keywords Autism $\cdot$ ADHD $\cdot$ iPad app $\cdot$ Complex drawing task

\section{Introduction}

Multisensory information from the world around us needs to be integrated, processed, organised and understood. Our ability to find patterns in the surroundings is often called "perceptual organisation" (Wagemans et al., 2012). Based on task demands, we use different types of perceptual organisation. The ability to extract the "big picture" is called global processing, and the ability to notice the details is called local processing (Simmons \& Todorova, 2018). We often use these two types of perceptual organisation interchangeably. However, distinct preferences have been reported in some populations (e.g. autism: Kandaloft, Didehbani \& Krawczyk, 2019; ADHD: Wang \& Reid, 2011).

S. Savickaite

sarune.savickaite@glasgow.ac.uk

1 School of Psychology and Neuroscience, University of Glasgow, Room 531, 62 Hillhead street, Glasgow G12 8QB, Scotland

2 Laboratory for Innovation in Autism, University of Strathclyde, Glasgow, UK
Autism spectrum disorder (ASD) ${ }^{1}$ is defined in the Diagnostic and Statistical Manual of Mental Disorders, Fifth Edition (DSM-5) as a condition characterised by difficulties with social communication, sensory processing and repetitive behaviours (American Psychiatric Association [APA], 2015). Motor issues associated with autism are becoming increasingly recognised and are considered by some to be a core aspect of the condition (Fournier et al., 2010; Trevarthen \& Delafield-Butt, 2013). A recent metaanalysis by NHS Digital (2016) suggests that over $1 \%$ of the UK population is diagnosed with ASD. The latest study by the Centers for Disease Control and Prevention in the United States suggests a prevalence of close to $2 \%$ there (Baio et al., 2018). Distinct cognitive and perceptual styles have been observed in autism (Baron-Cohen, 2004; Simmons et al., 2009), but there is, as yet, no theoretical consensus on the underlying causes.

An early attempt at explaining the apparently distinctive visual processing style in autism was the weak central

\footnotetext{
${ }_{1}$ ASD, autism and individuals with autism will be used interchangeably in this paper. Recent research on neurodiversity and person-first vs identity-first language suggests this is an appropriate use of terminology (see Bury, Jellett, Spoor \& Hedley, 2020).
} 
coherence (WCC) theory (Frith, 1989). The empirical basis of this theory was atypical perceptual organisation demonstrated in some visuospatial tasks, such as the embedded figures task and the block design task, and the differential impact of visual illusions (Happé, 1996). WCC suggests that autistic individuals outperform controls in these tasks due to "better attention to, and memory for, local details, but lessened global processing" (Fletcher-Watson \& Happé, 2019). Enhanced perceptual functioning (EPF) theory (Mottron, 2001; Mottron et al., 2006) offers a subtly different explanation, in terms of enhanced local processing in autism without the obligatory (even if detrimental to task performance) global precedence found in non-autistic individuals. Happé and Frith's (2006) revision of WCC ("weak coherence") proposed superior local processing as a default "cognitive style" which could be overridden by explicit instructions (see also Koldewyn et al., 2011). Empirical support for any form of local versus global processing differences between autistics and non-autistics has, however, been patchy, with one thorough meta-analysis suggesting that, at least in static patterns, the only robust effect was the disruption of speed of global performance by local noise (Van der Hallen et al., 2015). Even this result has been called into question (Chamberlain et al., 2017). Empirical research which has employed sizable samples and extensive test batteries paints a complex picture, with task performance varying with IQ, gender and age, as well as diagnostic status (Van Eylen et al., 2018). More recently, there is a suggestion that disruption of perceptuomotor coherence in the autism spectrum may be due, in part, to brainstem neuroanatomical and functional differences, especially noted in its subtle, but significant sensorimotor control differences (Bosco et al., 2019; Dadalko \& Travers, 2018; Delafield-Butt et al., 2021).

Further accounts also discuss the hypothesis that the processing method used by an autistic individual is more driven by the attentional demands of the task (Plaisted et al., 1999). For example, enhanced perceptual load (EPL) theory (Remington et al., 2012) posits that autistic individuals inherently possess enhanced perceptual abilities. Therefore, perceptually complex tasks are less demanding, and the remaining capacity can allow for more distractor processing. Dual-coding theory (Smith \& Milne, 2017), on the other hand, builds on Glyn Humphrey's model of object processing and describes two parallel routes for encoding spatial features. However, local and global processing in autism is still a highly debated topic without a clear consensus (see Simmons \& Todorova, 2018, for an overview). Moreover, similar debates around visual processing have extended to other neurodevelopmental conditions. For example, different performance on visuospatial tasks has been linked to both autism and attention-deficit/hyperactivity disorder in diagnosed groups (Wang et al., 2018).

Attention-deficit/hyperactivity disorder (ADHD) is defined in the DSM-5 as a neurodevelopmental disorder exhibiting patterns of inattention, hyperactivity and impulsivity (APA, 2013). Ebejer et al. (2012) estimated that 3-5\% of the adult population in the UK is affected by ADHD. Autism and ADHD often co-occur, with an estimated $30-50 \%$ of autistic adults meeting ADHD diagnostic criteria (Rau et al., 2020). Autism and ADHD are distinct but related conditions, and when they co-occur, they often interact (Taurines et al., 2012). According to the findings of Song and Hakoda (2015), children with ADHD demonstrated a reduced preference towards global processing, contradicting DSM-5 (APA, 2015) criteria where failure to pay close attention to detail was emphasised. This finding was further supported by Cohen and Kalanthroff (2019) and Kalanthroff et al. (2013), suggesting that individuals with ADHD may experience a local processing bias. Local and global processing styles are not as extensively researched as in autism, and therefore, no formulated theory is available. However, recent findings suggest that autism and ADHD may share similarities in their overall visual processing style that may explain the overlap of symptoms (e.g. behavioural issues, difficulties in social situations). Currently, the extent of this overlap remains unclear (Groom et al., 2017) and warrants further investigation.

Many different tasks have been used to investigate localglobal visual processing differences in Autism and ADHD, but one of the most popular has been the Rey-Osterrieth complex figure (ROCF). This task is an established test for visuospatial memory, sensory processing style and executive function (Molitor et al., 2018; Shin et al., 2006; Watanabe et al., 2005). The ROCF was designed in the 1940s (Osterrieth, 1944; Rey, 1941) and was originally used for neuropsychological assessment (Fig. 1). Participants are first asked to copy the figure. Then the figure is taken away and participants are asked to draw it again from memory. Often

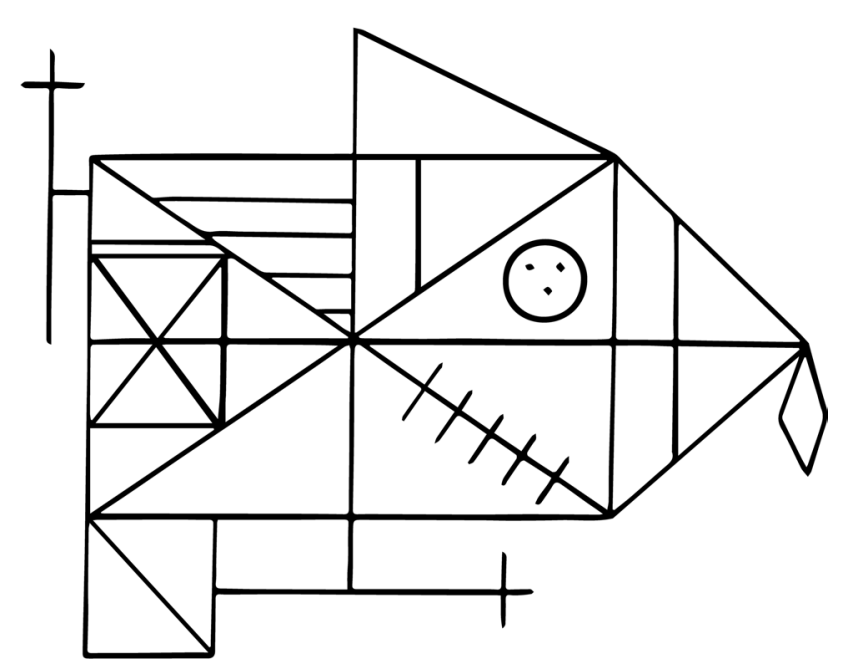

Fig. 1 The Rey Osterrieth Complex Figure 
a third recall condition is used where participants are asked to draw the figure again after a short delay. The ROCF has been used previously in local and global processing assessment in autistic and ADHD populations (Catanzaro, 2005; Kuschner et al., 2009; Minshew \& Goldstein, 2001; Schlooz et al., 2006; Seidman et al., 1995;Tsatsanis et al., 2011 ; Van Eylen et al., 2018).

Developmental studies of the ROCF are of particular interest to the current work. Akshoomoff and Stiles (1995a, 1995b) provided valuable insight into developmental changes in ROCF tasks. They found that, before the age of 9 years, neurotypical children struggled to appreciate the figure as a coherent whole, instead adopting a piecemeal approach. This is similar to the method of processing proposed in WCC theory, where global elements of ROCF, such as the large rectangle and intersecting lines are drawn first and details (small lines, diamond and the "little face") filled in later for "globally" inclined participants. The opposite would be expected in autistic and ADHD groups (Tsatsanis et al., 2011; Van Eylen et al., 2018). The ROCF has also been used as a measure of executive function in studies with individuals diagnosed with both ADHD and ASD, focusing on the organisational approach to the task. Akshoomoff and Stiles (1995b) found that the strategy adopted in the copy condition influences the manner in which children will draw it from memory, and therefore their overall performance.

The ROCF task is a widely used neuropsychological tool and the majority of literature on various scoring systems comes from clinical populations (e.g. epilepsy, individuals with brain lesions; Shin et al., 2006). In research into local and global processing in autism and ADHD, the most useful aspect of scoring is the ability to measure the features, primarily focusing on accuracy. Inclusion or absence of details may provide evidence for enhanced local processing and/or fragmented perception, often reported in first-hand accounts by autistics. Therefore, the perceptual and organisational scoring systems are the most suited for our study.

The nuances of how visual processing styles vary in neurodivergent individuals are still not fully understood. Different scoring systems for the ROCF task are an attempt to measure these nuances by altering which elements of the figure are considered most significant. However, in order to obtain a more complete account of performance in this task we should also measure temporal and kinematic aspects.

\section{Technological advances and their adaptation in research}

Mobile technology provides various useful features, including flexible multimedia content and storage, portability and affordability (Vlachou \& Drigas, 2017). Moreover, technological developments have integrated several movement and touch sensors into mobile devices such as phones and tablets, allowing unprecedented access to data on interaction accuracy and reliability (Millar, 2012). Mobile tools in neurodevelopmental research have been predominantly used for assessment and intervention, whereas computer-assisted learning (CAL) has been explored only recently (FletcherWatson, 2014). Technology-based approaches have been adapted for teaching literacy, emotion regulation and social skills. Research participants respond positively to technology and are often more verbal and interactive with touchscreen equipment (Fletcher-Watson et al., 2016).

Household tablet use increased from $8 \%$ in 2011 to $78 \%$ in 2017 (Kirkorian et al., 2020). Several studies have explored this rapid transition, predominantly in children, as it involves motor and cognitive elements. Growing access to touchscreen technology is one of the contextual factors contributing to development. Touchscreen technology is on track to replace the traditional forms of writing and drawing, and might have cascading effects on fine motor skills.

Kagohara et al. (2012) assessed the viability of iPads and similar technology for individuals with developmental disabilities. The majority of the 15 studies reviewed found positive results. Moreover, tablets have been successfully used in autism research (Vlachou \& Drigas, 2017; Loth \& Evans, 2019) for assessment, intervention and entertainment. Communication apps such as Speak4Yourself give a voice to non-verbal autistic individuals. Bishop (2003) reported on the PARLE app, which translates confusing language, such as metaphors, into easier meanings for autistic individuals to understand. Digital, specifically tablet, interventions have been found to raise social acceptance of augmented or alternative communication methods (Vlachou \& Drigas, 2017).

Similarly, Anzulewicz et al. (2016) successfully developed a novel, smart tablet game for early identification of autism in young children by collecting tablet sensor data (inertial and touch screen sensors). This particular app employs a serious game approach with machine learning for identification of preschool children with ASD useful in screening and diagnostic services, and is currently under Phase 3 multisite diagnostic trial (Millar et al., 2019). Children with motor challenges have been shown to need additional time to learn how to navigate the device, but engagement ratings made up for this downside. Tabletbased intervention in autism has been claimed to result in communication improvement, successful learning of basic concepts, more self-talk, monitoring and recording of real-time data (Chmiliar, 2017). Tablet-based serious games have also been investigated in other contexts, such as sensory processing differences (Zakari et al., 2017). In short, tablet-based drawing provides more useful data and, due to its familiarity and ease of use, is likely to be more engaging for participants than traditional pen-and-paperbased approaches. 


\section{ROCF task for tablets}

The quickly developing world of technology has significantly improved touch screen and pen tablet response time for handwriting and drawing tasks. The new Galaxy Note 20 has a $120 \mathrm{~Hz}$ refresh rate and a $9 \mathrm{~ms}$ response time (Samsung, 2020). The iPad was ranked as one of the most responsive touchscreen tablets in 2013 (Agawi, 2013). Although not the most advanced tablet in the market today, with the addition of the Apple Pencil (Apple, 2015), it is still one of the top devices used for handwriting and basic drawing tasks.

Improvement in the screen response time inevitably led to an adaption of classical "pen and paper" tests, such as the ROCF, for tablet technology. Riordan, Lombardo and Schulenberg (Riordan et al., 2013) found mixed results on how much participants preferred interacting with the tablet compared to the standard pen and paper ROCF task. Engagement with a novel tool, i.e. tablet, was rated favourably; however, participants preferred pen and pencil for the task itself. This study was published at a time when tablet functionality was not as advanced as it is now because the touch screen response and refresh rates were poor. The ROCF task was used again in 2018 to investigate executive function in ADHD. No differences from the pen and paper test were reported (Hyun et al., 2018). The task itself was the same as the standard version. The images were further analysed using Gaussian filters in MATLAB. The number of pixels was calculated and compared to the reference image of the ROCF. Although the automation of image extraction and processing is a good idea, it does not add any further information on performance in the task.

This paper will introduce an iPad-based app called LetsDraw, which enables free drawing on a blank canvas, and coordinates with timestamps can be exported to recreate the real-time interaction. The temporal dimension introduced in this experiment is a more efficient way to identify the order in which the elements of ROCF are drawn. Standard penand-paper tests often use different coloured pens to identify time increments, which is a cumbersome and crude method. Although additional measures of pressure and kinetics can be included in the data collection, for the purposes of this study we are introducing the temporal element only. We wish to test the feasibility of the tool before building on additional measures of performance.

\section{Feasibility study}

The aim of the feasibility study is to explore the relationship between autistic and ADHD traits, and ROCF scores using a tablet-based app. We expect decreased accuracy in delayed conditions; however, the effects of autistic and ADHD traits on the overall performance are difficult to predict, due to mixed results in current literature. Organisational scores, measuring how well participants comply with the global processing of the ROCF, are expected to decrease with higher scores on autism and ADHD questionnaires.

The app and the feasibility pilot study description will illustrate how the app can be used in research. The standard Rey-Osterrieth complex figure task will assess local and global processing in participants differing in autistic and ADHD traits. Although tablet devices have been used previously for the task in autism and ADHD (Canham et al., 2000; Hyun et al., 2018), none of them have yet combined spatial and temporal drawing measurements. Therefore, we cannot predict how temporal measures will be different between our participant groups. making this an exploratory study.

\section{Methods}

\section{Participants}

Data were collected between January and March 2019 at the School of Psychology, University of Glasgow. Participants were recruited via an online subject pool. Three out of the original 42 participants were excluded from the final analysis due to missing data. The mean age of participants was $21.8(\mathrm{SD}=2.4)$ years. Twenty-nine identified as female, eight as male and two as other; $69.2 \%$ of participants were native English speakers, and three out of 39 were left-handed. Most of the participants were undergraduate students at the University of Glasgow. Although age and educational background cannot be generalised to a wider population, our sample provides some cultural diversity, as not all were native English speakers. However, extra care must be taken when generalising data collected from such a sample, no matter how diverse. As this was a feasibility study we are accepting the limitations of our sample size and limited generalisability of the findings.

\section{Materials}

\section{Apparatus}

The task was completed using the LetsDraw app as described in the app description portion of this paper. An iPad Mini 2 (Retina/2nd Gen) $1.3 \mathrm{GHz}$ Apple A7 $1 \mathrm{~GB}$ model A1489 (EMC 2695*) was used for this experiment. Participants used their touch screens to draw the figure (i.e. using the finger and not the stylus). The size of the tablet was $200 \times 134.7 \times 7.5 \mathrm{~mm}$ and it was $331 \mathrm{~g}$ in weight. The second-generation iPad mini has a 7.9-inch (diagonally) 
LED backlit multi-touch display with IPS technology and a resolution of 326 pixels per inch. The screen refresh rate is $60 \mathrm{~Hz}$.

\section{LetsDraw app}

The LetsDraw app is an extension of studyDraw (Lux, 2016) developed by Erin Lux at the University of Strathclyde using the Swift programming language via XCode $(2003)^{2}$.

Basic XCode knowledge will be sufficient to manipulate and run the app together with the detailed description provided in the supplementary materials at https://sites.google. com/view/letsdrawapp.

Apple continuously updates their software, and the iOS must be up to date on the home device (i.e. laptop/desktop computer) and the test device (i.e. iPad/iPhone) ${ }^{3}$. In addition, XCode has recently been updated to the XCode Beta (2020) version, which has slightly modified the initial code of the app. The original code has now been debugged and updated for future use. However, the functionality described in this paper has not been altered by this update.

The test device used for this paper was an iPad mini 2 (Retina/2nd Gen) $1.3 \mathrm{GHz}$ Apple A7 1 GB model A1489 (EMC 2695*). Once the build has been successful the app will be automatically installed onto the test device.

When opened, the app will display a blank screen with a New option in the middle. Pressing this option will start the session. The next screen will ask the user to name the session. This name will later be extracted with the rest of the data from the session. The next screen will have two options: Start and Restart. Restart allows the user to go back to the beginning in case of an error.

Finally, a blank canvas will be presented where the drawing can be completed. This screen will be displayed for the length of time preselected in the code. When the session is finished the original screen with the New option will appear again. This will allow the next run. The app can be terminated by pressing the "Home" button on the device.

Multiple sessions can be run on the test device and each one will be recorded and stored. In order to extract the data, the test device will have to be connected to the home device. Each file is saved as a .csv ${ }^{4}$ file, which includes $\mathrm{x}$ and $\mathrm{y}$

\footnotetext{
${ }^{2}$ XCode is an integrated development environment developed for macOS by Apple in 2003. It predominantly uses the Swift programming language, which is based on $\mathrm{C}++$ and Java.

${ }^{3}$ Home device (i.e. laptop or desktop computer) and test device (i.e. iPad or iPhone) will be used as shorthand terms in this paper to describe the device containing the XCode (home) and the device which is used to run the experiment (test).

${ }^{4}$.csv file format stands for comma-separated values, and it is a delimited text file which uses commas to separate values. It is the file format used for the majority of data analysis programmes, including R.
}

coordinates and timestamps. Time elements are recorded every $16 \mathrm{~ms}$, which results in approximately 1500 data points. This allows for the most accurate representation of the figure drawn; however, future iterations of the experiment could investigate the minimum number of data points required for the accurate representation of the figure.

\section{Questionnaires}

\section{Autism Spectrum Quotient (AQ)}

The Autism Spectrum Quotient (AQ) is a self-report questionnaire designed to measure levels of autistic traits in adults of typical intelligent (IQ > 70) (Baron-Cohen et al., 2001). The questionnaire is composed of 50 questions, with five subscales with moderate internal consistency: social skills (Cronbach's $\alpha=0.77$ ), attention-switching (Cronbach's $\alpha=0.67$ ), attention to detail (Cronbach's $\alpha=0.63$ ), communication (Cronbach's $\alpha=0.65$ ) and imagination (Cronbach's $\alpha=0.65$ ).

Questionnaires were scored using standard scoring systems (Baron-Cohen et al., 2001). Answers to each question of the AQ were scored as either 0 or 1 (see Appendix B for details). The maximum score is 50; however, scores over 26 are often considered to signify diagnosable autism (Woodbury-Smith et al., 2020). The AQ has been found to be a good tool for investigating the continuum of autistic expression in the general population and has been used extensively (Ruzich et al., 2016). Internal consistency and test-retest reliability of the questionnaire are largely consistent throughout different demographics and cultures (Broadbent et al., 2013; Lau et al., 2013; Stevenson \& Hart, 2017).

\section{Adult ADHD Self-Report Scale v1.1 (ASRS v1.1)}

The Adult ADHD Self-Report Scale (Appendix B) is a selfreport questionnaire consisting of 18 items with a Likert scale scoring system (Kessler et al., 2005). ASRS v1.1 has good sensitivity and specificity for detecting ADHD traits. Internal consistency ranges from 0.63 to 0.72 (Kessler et al., 2007). ASRS v1.1 (Kessler et al., 2005) is an 18-item questionnaire scoring between 0 and 4 (Appendix C). A maximum is 72 ; however, the first six questions are considered to be the most indicative of ADHD traits. This questionnaire has consistently shown high convergent validity, correlation of subscales and test-retest reliability throughout different demographics and cultures (Silverstein et al., 2017; Evren et al., 2016).

\section{Procedure}

The study was conducted in accordance with the University of Glasgow and Economic and Social Research Council 
(ESRC) ethical guidelines. Participants gave informed consent before the experiment. The Rey-Osterrieth complex figure was presented on a computer screen and participants were asked to copy the figure using the LetsDraw app on an iPad mini (Fig. 2).

For the Copy condition, participants were seated in front of the computer, approximately $50 \mathrm{~cm}$ from the monitor. The ROCF image was presented as a full-screen image on a standard 23-inch LCD Acer monitor (resolution $=1920 \times 1080$ pixels, refresh rate $=59 \mathrm{~Hz}$, mean luminance $=60 \mathrm{~cd} / \mathrm{m}^{2}$ ), run on a Dell desktop computer. The ROCF image was a black line drawing on a white background. The iPad with the app already open and ready for drawing was placed in front of the participant.

After the Copy condition, the image on the computer screen was removed and participants were asked to draw the ROCF figure from memory. After the Immediate Recall condition, participants were asked to complete the AQ and ASRS questionnaires which were presented using Microsoft Forms on the computer. Once the questionnaires were complete, participants were asked to draw the ROCF figure from memory again. The delay time varied between participants, thus suggesting that the break was cognitive rather than temporal. This is a slight departure from the standardised procedure of the pen-and-paper ROCF task. Autistic and ADHD (Sørensen et al., 2017) individuals generally do not favour long delays between tasks; thus the decision was made to allow participants take breaks suitable for them. Once the Delayed Recall condition was completed, participants were debriefed. The whole experiment lasted approximately 30 minutes.

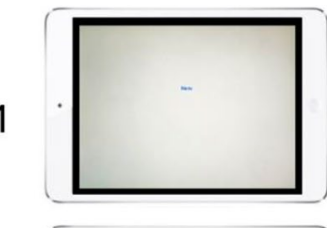

2
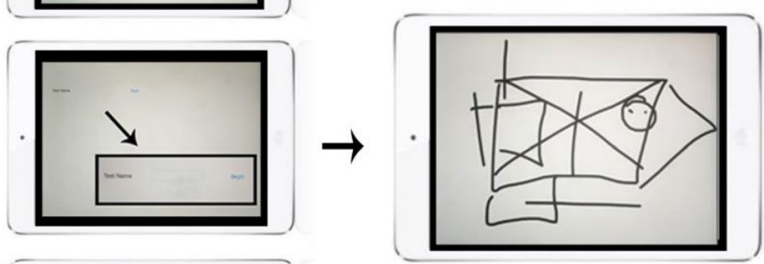

3

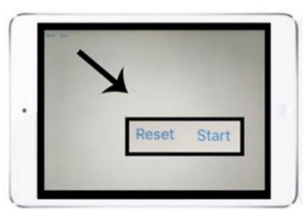

Fig. 2 Stages of running the LetsDraw app: (1) new session started; (2) test name selected; (3) start and reset option available. The image on the right shows an example drawing from the feasibility study described later in the text

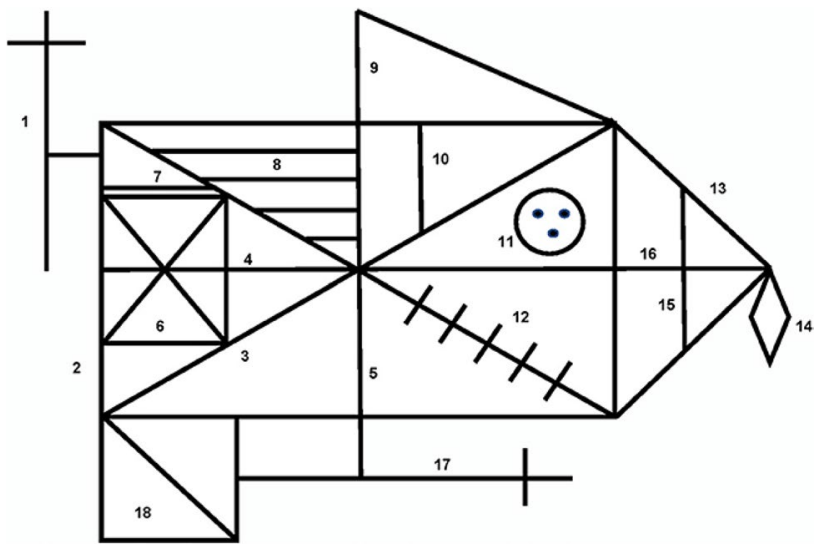

Fig. 3 The perceptual scoring system for the ROCF (Booth, 2006; Osterrieth, 1944)

\section{ROCF scoring}

The perceptual scoring system was initially devised by Osterrieth (1944) and later adapted by Booth (2006). Each figure is scored using 18 features (Fig. 3). Two points are given if the feature is placed correctly, and one point given if it is incomplete or placed poorly. The maximum score possible is 36 . The perceptual scoring system captures the accuracy of the task (Appendix C). This perceptual scoring system provides a quantitative measure of accuracy of reproduction of the task. It lacks qualitative analysis of performance and does not provide insight into other aspects of the task, such as processing style and planning subjectivities. However, inter-rater reliability can be as high as 0.99 (Mitrushina et al., 2005). Several qualitative scoring systems have been used alongside the standard perceptual scoring system (Osterrieth, 1944). Poreh and Ed.). (2012) describes numerous scoring systems with overlapping measures; however, they are all from the 1980s and have not re-emerged in recent literature.

An alternative is the Boston Qualitative Scoring system (BQS), which was devised by Stern et al. (1999), and it provides both quantitative summary scores and qualitative assessment of performance on the task. Inter-rater reliability determined by Kappa coefficients is high for most scores on the scale; however, some scores were considerably lower for scoring facets such as cluster and detail placement, rotation and neatness (Brauer Boone, 2000). Moreover, the BQS is not open-source and therefore could not be used in our study. As an alternative, we have selected the organisational scoring system by Hamby et al. (1993), which assesses the organisation and captures the quality of the approach taken to complete the task. It is often used alongside the BQS (Shin et al., 2006) and therefore, has been chosen as an alternative for our study.

The organisational scoring system was designed by Hamby et al. (1993) to evaluate organisational ability. Scores range 
from 1 to 5 , where 1 is awarded for very poor organisation and 5 stands for excellent organisation. The full procedure for the organisational scoring is available in the online supplementary materials. The time element available from the LetsDraw app allows for more accurate organisational scoring, which relies on the order in which elements were drawn.

Two scorers, both authors on this paper, evaluated each drawing. No specialised training was required, as clear instructions on how scoring should be performed are available for both scoring systems (see online supplementary materials). Scorers assigned individuals scores independently and the mean score was used in further data analysis. There were no large discrepancies between the scores (Pearson's correlation for differences in perceptual scores, $r(115)=0.96, p<0.001$; and Cohen's kappa $=0.74, p<0.001$ for organisational scores). As the scoring systems used are quantitative in nature, the subjectivity of each scorer did not affect the overall result.

\section{Analytic plan}

Shapiro-Wilk tests indicated that data were approximately normally distributed, allowing for the use of parametric inferential statistics. The independent variables (AQ and ASRS scores) were entered into multiple linear regression models to investigate how well they predicted the dependent variables (perceptual and organisational scores) across the experimental conditions.

\section{Results}

The internal consistency as measured using Cronbach's alpha was good for both the AQ $(\alpha=0.64)$ and ASRS questionnaires $(\alpha=0.82)$. AQ scores ranged from 2 to 36 , with a mean score for the sample of $16.82(\mathrm{SD}=8.37)$. ASRS scores ranged from 12 to 59, with a mean score of $30.95(\mathrm{SD}=11.59)$. Both AQ and ASRS scores demonstrated a wide range of traits in our sample. Scores of the two questionnaires did not show a significant correlation, $r(37)=0.22, p=0.18$ (Fig. 4).

The mean perceptual score for the Copy condition was $34.2(\mathrm{SD}=1.93)$ and the mean score for organisational score was $3.33(\mathrm{SD}=1.08)$. The Copy condition was completed on average in $89.2 \mathrm{~s}(\mathrm{SD}=17.1)$. A significant correlation was found between scores obtained using the two scoring systems, $r(37)=0.62, p=0.001$, for this condition. The mean perceptual score for the Immediate Recall condition was lower, $26.03(\mathrm{SD}=0.504)$. However, the organisational score was slightly higher, $3.487(\mathrm{SD}=1.2)$. Completion time was similar to the Copy condition with a mean time of $85.3 \mathrm{~s}(\mathrm{SD}=20.8)$. Organisational and perceptual scores correlated again, $r(37)=0.68, p=2.136 \times 10^{-6}$. The average

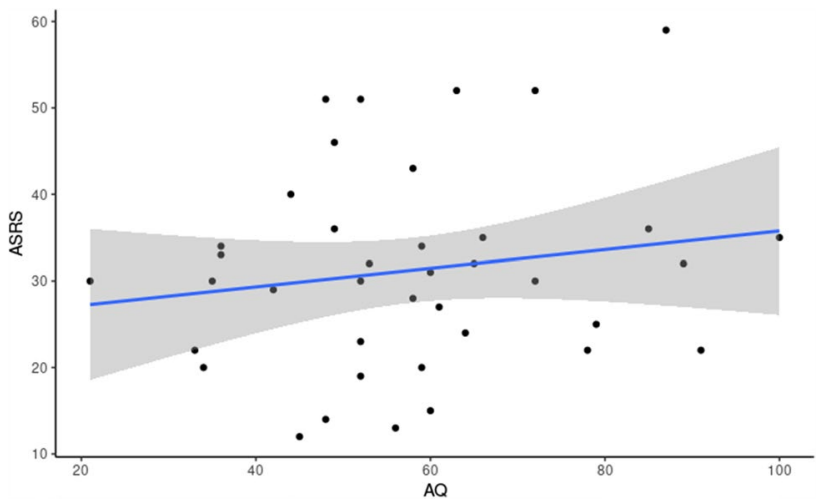

Fig. 4 Scatterplot showing the relationships between AQ and ASRS questionnaire scores, $r(37)=0.22, p=0.18$

perceptual score was lowest for the Delayed Recall condition, $25.9(\mathrm{SD}=4.7)$. The organisational score was similar to the previous conditions, $3.56(\mathrm{SD}=0.912)$. Completion time reduced to $68.6 \mathrm{~s}(\mathrm{SD}=19.1)$. A strong positive correlation was observed again between organisational and perceptual scores, $r(37)=0.61, p=4.461 \mathrm{e}-5$. Visual representation of the differences between the two scoring systems across all three experimental conditions is presented in Fig. 5.

To investigate the effects of the AQ and ADHD subscales on ROCF performance, two multiple linear regression models were implemented for perceptual and organisational scores, the results of which are presented in Table 1. The residuals of the models were normally distributed. The models were found to be significant for both perceptual (adjusted $R^{2}=0.47, F(9,107)=12.48, p<0.001$ ) and organisational score (adjusted $R^{2}=0.19, F(9,107)=4.10$, $p<0.001$ ). Significance for the model of perceptual scores seems to have been mainly driven by the differences in perceptual scores between the conditions. Table 1A shows significant differences between the Copy condition and both Immediate Recall and Delayed Recall conditions. This is further illustrated by Fig. 5a, where this difference can be visualised. Organisational scores, however, did not show a significant difference between the three experimental conditions (Fig. 5b and Table 1B). The significance of the model seems to have been driven by AQ subscales, where attention to detail (higher score $=$ higher attention to detail) and communication (higher score $=$ difficulties with communication) were positive predictors and attention-switching (higher score $=$ difficulties with attention-switching) was a negative predictor of the performance on the task. Higher scores on attention to detail and communication have successfully predicted higher organisational scores, suggesting that this subscale is important in global processing tasks, whereas higher scores on the attention-switching subscale predicted lower organisational scores and therefore local processing bias Table 2 . 


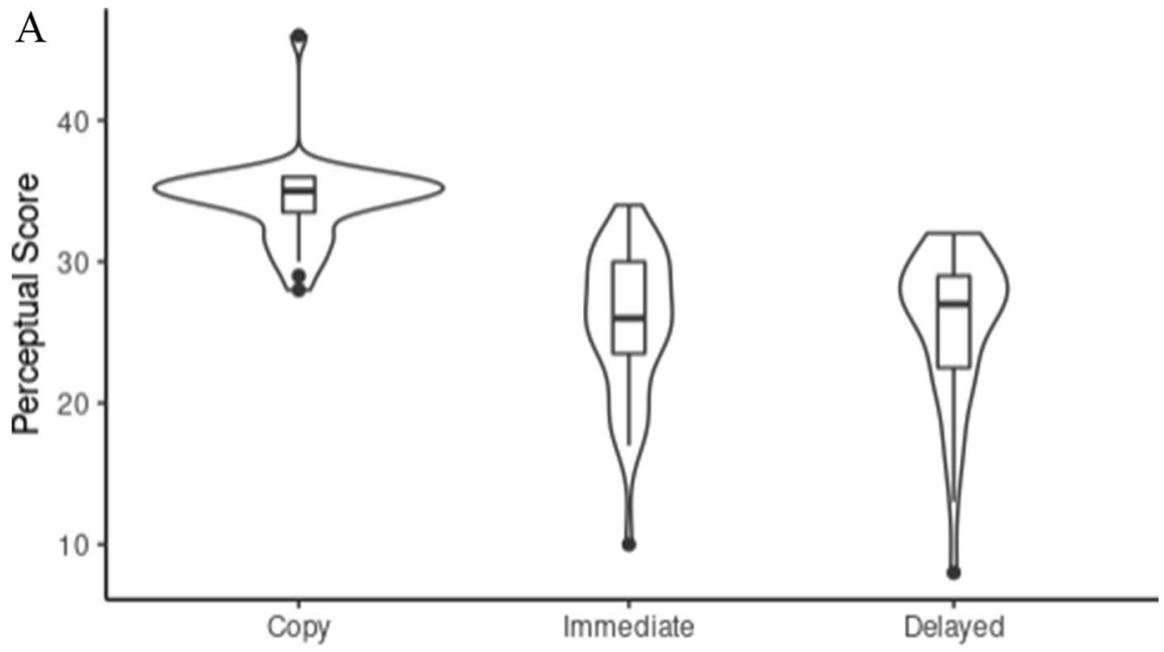

B

Condition

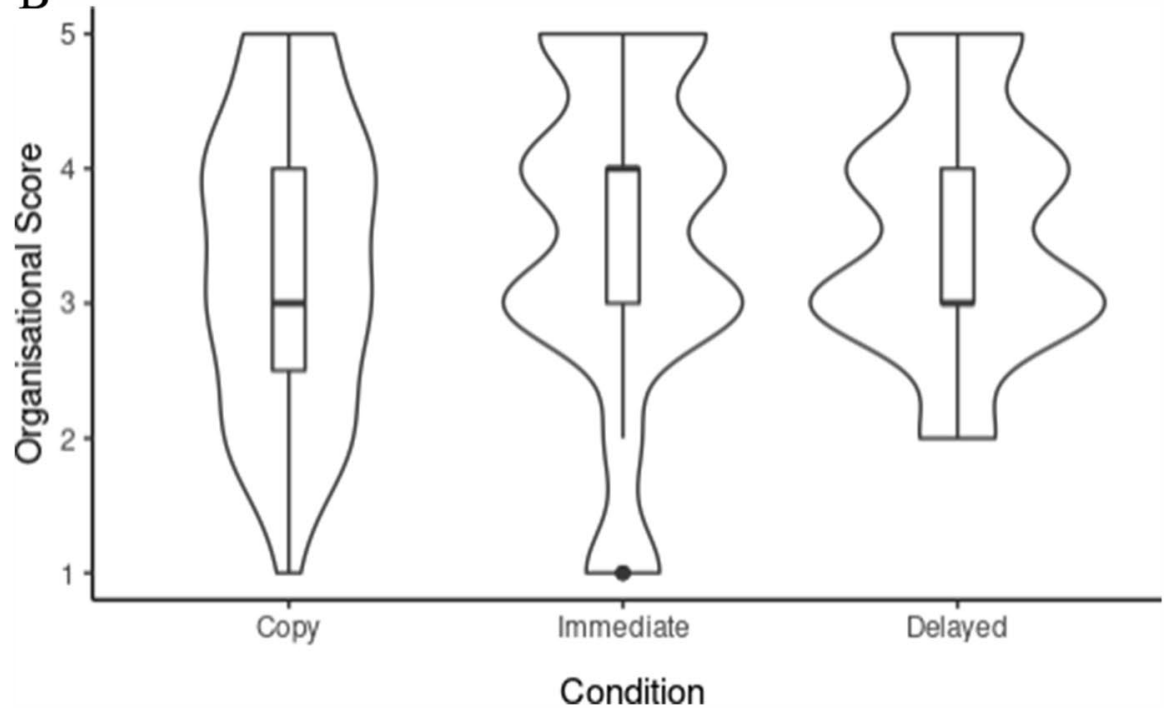

$\mathrm{C}$

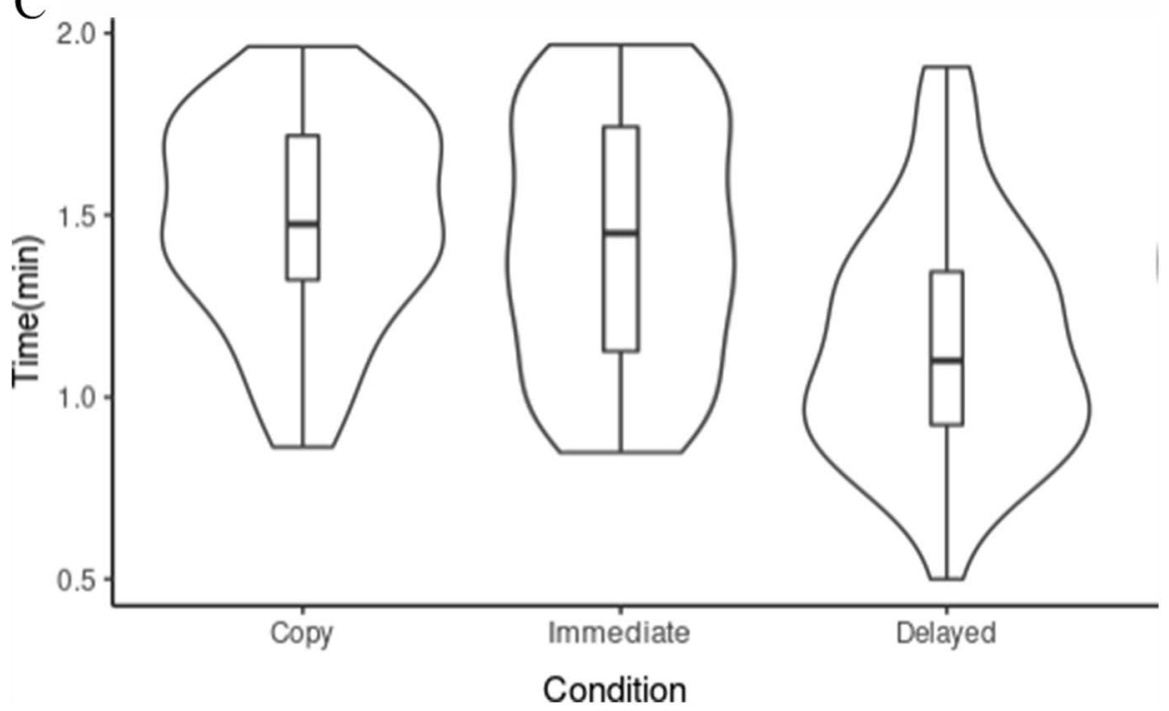

Fig. 5 Visual comparison of ROCF scoring between Copy, Immediate Recall and Delayed Recall conditions. a Perceptual scores; b organisational scores, $\mathbf{c}$ completion time 
Table 1 Coefficients from multiple linear regressions of perceptual (A) and organisational (B) ROCF scores. Significant predictors are highlighted.

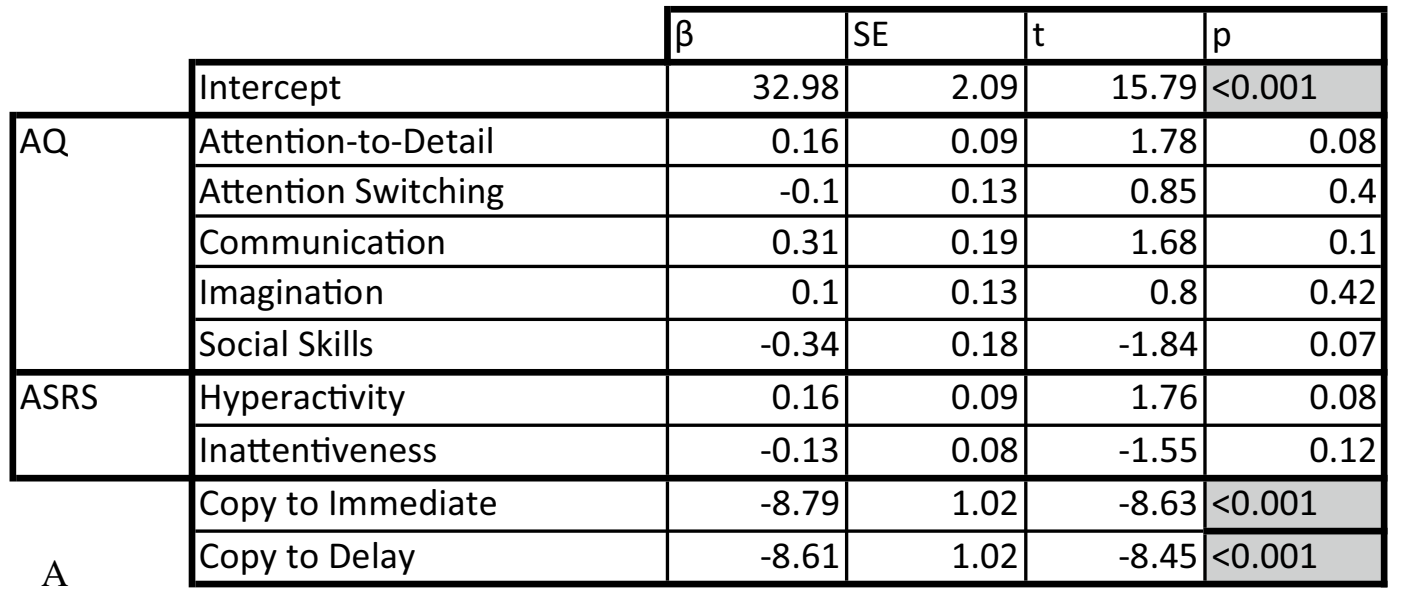

\begin{tabular}{|c|c|c|c|c|c|}
\hline & & $\beta$ & SE & $\mathrm{t}$ & $p$ \\
\hline & Intercept & 2.33 & 0.45 & 5.23 & $<0.001$ \\
\hline \multirow[t]{5}{*}{$A Q$} & Attention-to-Detail & 0.05 & 0.02 & 2.8 & 0.006 \\
\hline & Attention Switching & -0.06 & 0.03 & -2.39 & 0.02 \\
\hline & Communication & 0.1 & 0.04 & 2.5 & 0.01 \\
\hline & Imagination & 0.03 & 0.03 & 1.2 & 0.23 \\
\hline & Social Skills & -0.05 & 0.04 & -1.33 & 0.19 \\
\hline \multirow[t]{2}{*}{ ASRS } & Hyperactivity & 0.04 & 0.02 & 1.92 & 0.06 \\
\hline & Inattentiveness & -0.004 & 0.02 & -0.27 & 0.79 \\
\hline \multirow[b]{2}{*}{ B } & Copy to Immediate & 0.23 & 0.22 & 1.06 & 0.29 \\
\hline & Copy to Delay & 0.15 & 0.22 & 0.7 & 0.48 \\
\hline
\end{tabular}

Coordinates were plotted with the time element to visualise the data. An example of the visualisation is presented in Table 1. Introducing completion time allows precise visualisation of the way participants completed the drawing for each individual condition. In Fig. 6 we present data from Participant 3 and break down the overall performance into three equal time intervals to identify which elements of the ROCF were drawn first. The Copy and Immediate Recall conditions appear to show some global preference, where larger elements, such as the rectangle and longer definitive lines, are drawn first. This preference appears to be more distinct in the Delayed Recall condition. A tendency towards a more global processing style in the Delayed condition is reflected in the organisational scores (see Fig. 5b).

In order to assess how the temporal data compared to the organisational scores, all of the drawings were coded in a binary code, where a score of 1 (global processing) was assigned to drawings where global elements were drawn first, and a score of 0 (local processing) was assigned to drawings where local elements were drawn first. These were plotted against organisational scores (Fig. 7).

\section{Discussion}

The aim of this feasibility study was to explore the utility of an iPad-based ROCF task. We were also interested in the relationship between autistic/ADHD traits and ROCF scores obtained with this new digital method.

In terms of feasibility, participants were happy to use the LetsDraw app to perform the task. The key advantage of the app over traditional colour-coded crayon-based methods (e.g. Tsatsanis et al., 2011), is that temporal aspects of the drawing sequence can be reconstructed in full, without 


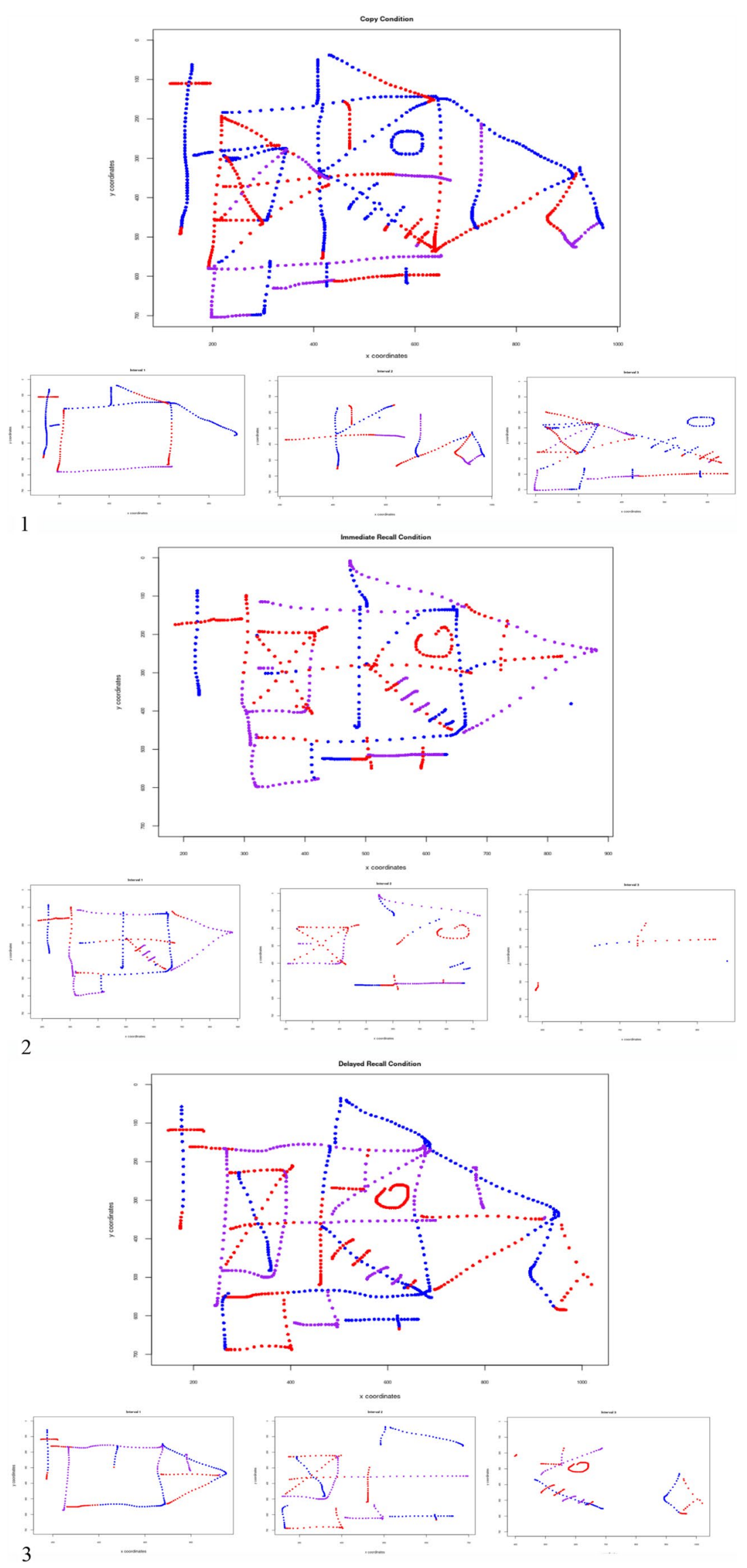


4Fig. 6 Visual recreation of drawings made by Participant 3 for all experimental conditions: Copy (1), Immediate Recall (2) and Delayed Recall (3). Additional subplots represent elements drawn at separate time intervals. The colour transitions represent how the figure changed over time (blue - elements drawn first, red - elements drawn last).

having to video-record the participant, as shown in Fig. 6, and this advantage was realised in our data analysis. Figure 7 is a graphical representation of the relationship between organisational score and the assigned category $(1=$ global processing style; $0=$ local processing style) to individual drawings of each participant by condition. Organisational scores have been arranged in descending order to illustrate the relationship between processing style and score. Organisational scores had fairly similar distributions throughout the three experimental conditions, although only Immediate Recall-Copy scores correlated significantly, $r(37)=0.75$, $p<0.01$. It is evident, however, that the number of drawings assigned to the local processing category increase in the Delayed Recall condition, suggesting that participants seem to adopt a different strategy for drawing from memory.

As for the results we obtained, although diagnosed autism and ADHD have previously been found to be related conditions (Chantiluke et al., 2014), there was no significant correlation between AQ and ASRS scores in our sample. We have used a sample with variable autistic and ADHD traits. Although a relationship between autism and ADHD has been previously observed in the general population (Geurts et al., 2013), it is possible that autistic and ADHD traits correlate in domains not captured by the questionnaires we used, or there could be additional confounding variables contributing to the results we have observed.

ROCF perceptual scores and completion time were significantly different between the conditions. In contrast, ROCF organisational scores did not show this pattern (see Table 1). These results, with the exception of organisational score, were expected at the start of the experiment. The Copy condition often takes the longest to process as it is an abstract figure that most participants have never seen before. It is also the most accurate as the image is visible and participants do not have to rely on their memory.

AQ and ASRS subscales did not predict perceptual ROCF scores, however, an interesting pattern emerged for the organisational ROCF scores. The attention-to-detail, attention-switching and communication subscales of the AQ were found to be predictive of organisational ROCF scores. The organisational scoring system (see online supplementary materials for full details) awards higher scores for a global completion of ROCF task. In other words, if the participant draws the rectangle and cross-over lines first and fills in smaller details ("little face", diamond and small boxes) later, the maximum points are awarded (Fig. 8). Points can be reduced if lines do not meet and smaller elements are disconnected. In our data, if participants scored higher on the attention-to-detail AQ subscale their organisational scores were significantly higher. Although previous findings have identified differences between the attention-to-detail subscale of the AQ in facial recognition (Davis et al., 2017), our study demonstrates a new idea that this subscale can be linked to visual processing and individual cognitive styles in a general population sample (see also Van Eylen et al., 2018).

Moreover, the attention-switching subscale of the AQ had a significant negative relationship with the organisational scores. High scores on this subscale of the AQ suggest poorer attention-switching ability. Our finding demonstrates that participants with flexible attention-switching had lower organisational scores, potentially suggesting that they have adopted a local processing style. The attention-switching subscale has been previously linked to ADHD (Cepeda, Cepeda \& Kramer, 2000; Dibbets et al., 2010), however, our findings do not support this link (as the AQ and ASRS questionnaires did not show a significant correlation). Perhaps, previous links between AQ and ASRS questionnaires have been driven by the subscales of the AQ. Previous work suggests that $\mathrm{ADHD}$ and autism might share common aetiology; however, it is not clear how each subscale of the two questionnaires are related (Concerto et al., 2021; Dalbudak \& Evren, 2014; Panagiotidi et al., 2018; Panagiotidi et al., 2019).

Finally, the communication subscale was also found to be a significant predictor of participants' performance and organisational scores. Higher scores on the communication subscale of the AQ suggest greater challenges with communication. Participants with higher scores on the communication subscale were more organised and had higher organisational scores in our sample. Challenges with social cognition, emotion recognition and communication skills have been previously linked to autistic traits, but results are inconclusive (McKenzie et al., 2018; Oerlemans et al., 2013).

Organisational scores were expected to correlate negatively with the AQ (Luna et al., 2007); however, our results suggest that higher autistic trait levels were associated with better organisation. Moreover, completion times were no longer in participants with higher AQ scores, contradicting our prediction that autistic traits affect executive function and specifically motivation in the task (Ferraro et al., 2018). Our results challenge the notion that autistic traits are associated with reduced global and enhanced local processing as proposed by the Weak Coherence theory that attends exclusively to perceptual information 


\section{COPY}

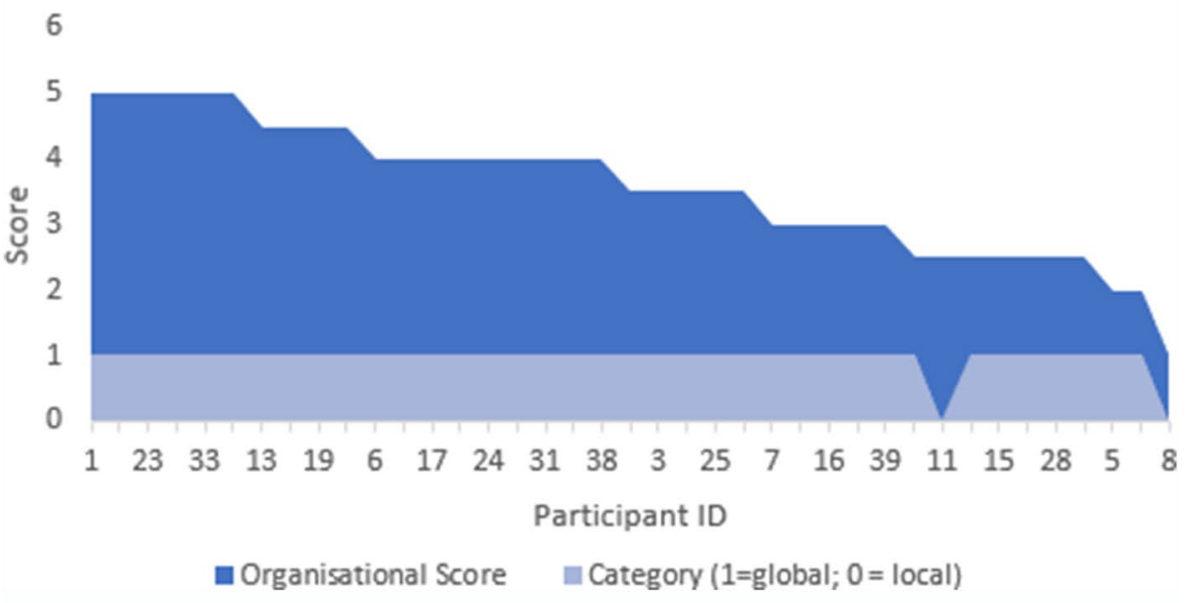

\section{IMMEDIATE}

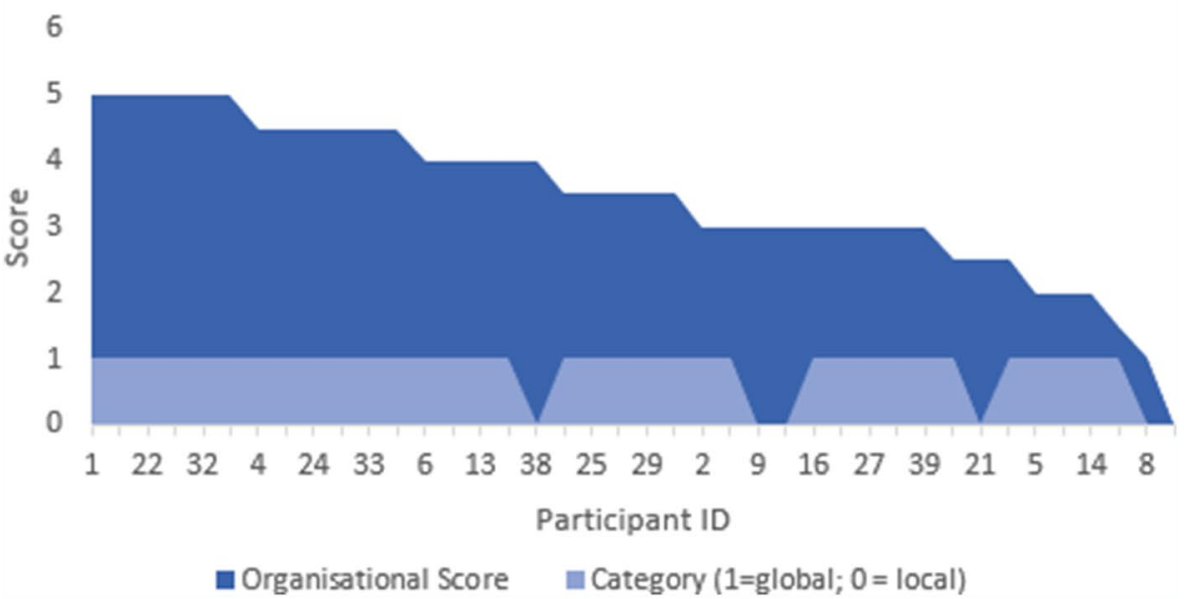

\section{DELAYED}

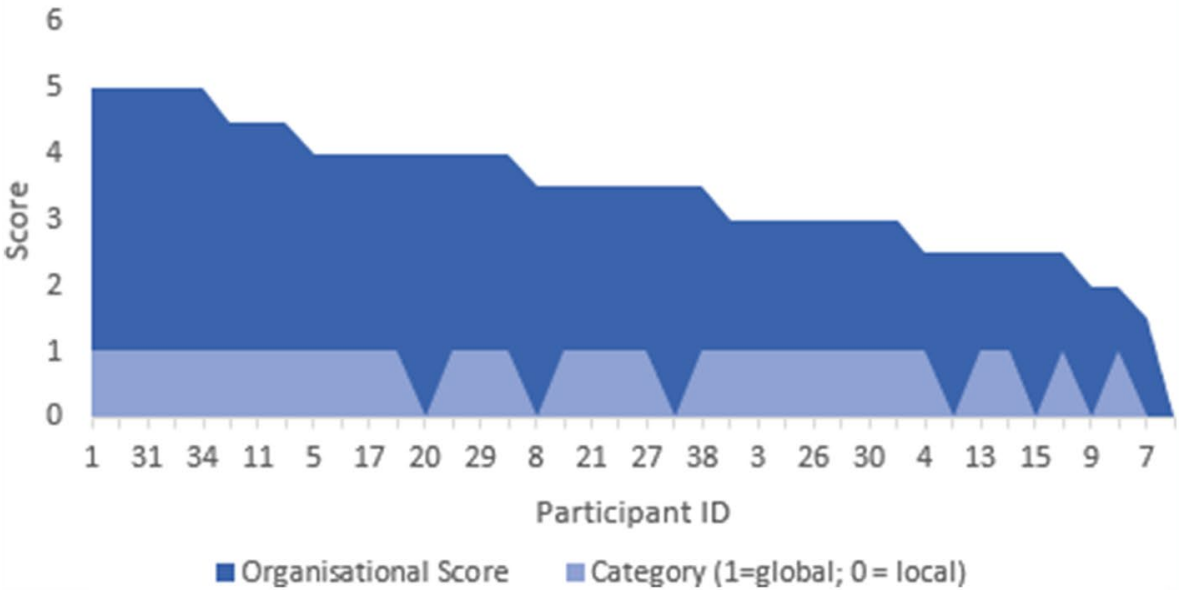

Fig. 7 Graphical representation of the relationship between organisational score and the assigned category $(1=$ global processing style; $0=$ local processing style) to individual drawings of each participant by condition. Organisational scores have been arranged in descending order to illustrate the relationship between processing style and the score. 


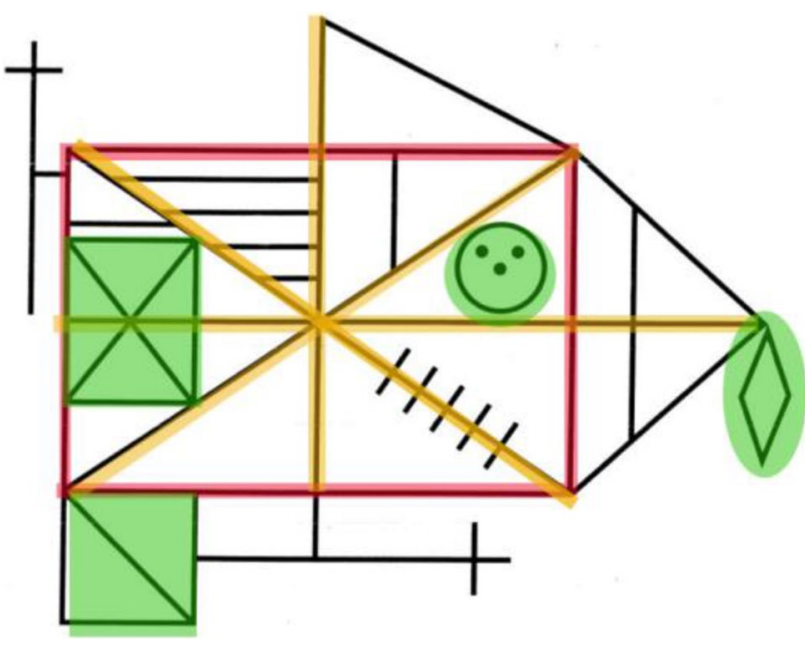

Fig. 8 Visual representation of global processing style of the ROCF. Red and yellow lines indicate elements drawn first and green highlights details completed last.

(Shah \& Frith, 1993). Similar results for a different task have been found by Hayward et al. (2018).

\section{Limitations}

One of the limitations of the current study is its relatively small sample size. A group of 39 participants does not meet the recommended number for correlations (Bonett \& Wright, 2000) or multiple regression models (VanVoorhis \& Morgan, 2007). However, previous ROCF studies have successfully used similar sample sizes $(N=37$, see Kuschner et al., 2009). Moreover, our sample solely consisted of undergraduate students, and thus our results could not be generalised to the general population. Participants were mostly female and the age range of 18-25 was limited. However, as noted previously, ADHD and autism are both neurodevelopmental conditions and therefore the presentation may follow different developmental trajectories for males and females, with earlier onset for males. Given that the ROCF will likely be of interest to child/adolescent providers, these developmental considerations will need to be accounted for when using the ROCF app with these younger populations. We did not collect additional information on participants' mental health. Many other conditions have been previously linked to variable performance in ROCF task, such as eating disorders (Eisenberg et al., 2011; Lang et al., 2016).

The technology employed in similar, recent drawing experiments is mixed. There is no consistency in medium: some use older models of touch-screen technologies, others incorporate a pen or a stylus into their studies (Hyun et al., 2018). Future studies should explore the advantages and disadvantages between media in more depth, especially as drawing with a finger on a touch screen involves different muscle groups and different friction characteristics from drawing with a pen. Moreover, the tactile response from traditional pen and paper drawing will differ from the pen/stylus used in many of the tablets used today (Kirkorian et al., 2020)

Finally, the surprising findings of the link between scores on the attention-to-detail subscale of the AQ and organisational scores warrant further investigation. Questionnaires with focus on executive function, such as the Executive Function Index (EFI; Ferraro et al., 2018), should be employed in order to further explore the meaning of this effect.

\section{Conclusion}

The LetsDraw app is a novel data collection tool which enables the fast visualisation and analysis of drawing tasks. This feasibility study has highlighted probable associations between higher autistic traits and organisational performance in the ROCF task. An association between autistic traits and time to complete the task was, however, not supported. ADHD traits were not found to be associated with perceptual and organisational scores in the task, nor the time it took to complete the task. These results provide a preliminary suggestion that autistic traits are in some way related to enhanced abilities in perceiving local and global aspects of the figure and relate higher autistic trait levels to better organisation, contrary to some existing theories of autistic perception.

Further feasibility studies of the new methodology used in this experiment should be explored. Data extracted from this digital translation of the ROCF lends itself to further, additional analyses. New computational measures include accuracy and computation of the fine motor control kinematics employed to carry out the drawing, include the possibility to include and test theories of the prospective organisation of movement thought to be disrupted in autism, but not in ADHD (Trevarthen \& Delafield-Butt, 2013). The addition of the Apple Pencil would afford pressure detection, which is important in motor organisation. Ultimately, the task's metrics of interest may be automated to allow quicker identification of visual processing strategies adopted. It can also be further adapted to explore alternative drawing tasks to shed light on perceptuo-motor properties of neurodevelopmental conditions. 


\section{Appendix A}

Table 2 AQ Questionnaire

definitely agree $\quad$ slightly agree $\quad$ slightly disagree $\quad$ definitely disagree

1. I prefer to do things

1

1

with others rather

1

than on my own.

2. I prefer to do things

the same way over

and over again.

3. If I try to imagine something, I find

it very easy to

create a picture

in my mind.

4. I frequently get

so strongly

absorbed in one

thing that I lose

sight of other things.

5. I often notice small sounds when others do not.

6. I usually notice car

number plates or

similar strings

of information.

7. Other people

frequently tell me

that what I've said

is impolite, even

though I think

it is polite.

8. When I'm reading

a story, I can easily

imagine what the

characters might

look like.

9. I am fascinated

by dates.

10. In a social group,

I can easily keep

track of several

different people's

conversations.

11. I find social

situations easy.

12. I tend to notice

details that others do not.

13. I would rather go to a library than a party.

14. I find making up stories easy.

15. I find myself drawn more strongly to people than to things.

16. I tend to have

very strong interests which I get upset about if I can't pursue.

17. I enjoy social chit-chat.

1

1

1

1

1 
Table 2 (continued)

definitely agree slightly agree slightly disagree definitely disagree

18. When I talk, it isn't always easy for

others to get a

word in edgeways.

19. I am fascinated by numbers.

1

20. When I'm reading a story, I find it

difficult to work out

the characters' intentions.

21. I don't particularly enjoy reading fiction.

22. I find it hard to make new friends.

23. I notice patterns in things all the time.

24. I would rather go to the theatre than a museum.

25. It does not upset me if my daily routine is disturbed.

26. I frequently find that I don't know how to keep a conversation going.

27. I find it easy to "read between the lines" when someone is talking to me.

28. I usually concentrate more on the whole picture, rather than the small details.

29. I am not very good at remembering phone numbers.

30. I don't usually notice small changes in a situation, or a person's appearance.

31. I know how to tell if someone listening to me is getting bored.

32. I find it easy

to do more than one thing at once.

33. When I talk on the phone, I'm not sure when it's my turn to speak.

34. I enjoy doing things spontaneously.

35. I am often the last to understand the point of a joke.

36. I find it easy to work out what someone is thinking or feeling just by looking at their face.

37. If there is an interruption, I can switch back to what I was doing very quickly.

1

1

1

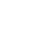

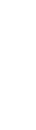

1

1


Table 2 (continued)

\begin{tabular}{|c|c|c|c|c|c|}
\hline & & definitely agree & slightly agree & slightly disagree & definitely disagree \\
\hline 38. & $\begin{array}{l}\text { I am good at social } \\
\text { chit-chat. }\end{array}$ & & & 1 & 1 \\
\hline 39. & $\begin{array}{l}\text { People often tell } \\
\text { me that I keep going } \\
\text { on and on about } \\
\text { the same thing. }\end{array}$ & 1 & 1 & & \\
\hline 40. & $\begin{array}{l}\text { When I was young, } \\
\text { I used to enjoy playing } \\
\text { games involving } \\
\text { pretending } \\
\text { with other children. }\end{array}$ & & & 1 & 1 \\
\hline 41. & $\begin{array}{l}\text { I like to collect } \\
\text { information about } \\
\text { categories of things } \\
\text { (e.g. types of car, types } \\
\text { of bird, types of train, } \\
\text { types of plant, etc.). }\end{array}$ & 1 & 1 & & \\
\hline 42. & $\begin{array}{l}\text { I find it difficult } \\
\text { to imagine what } \\
\text { it would be like to } \\
\text { be someone else. }\end{array}$ & 1 & 1 & & \\
\hline 43. & $\begin{array}{l}\text { I like to plan any } \\
\text { activities I participate } \\
\text { in carefully. }\end{array}$ & 1 & 1 & & \\
\hline 44. & I enjoy social occasions. & & & 1 & 1 \\
\hline 45. & $\begin{array}{l}\text { I find it difficult } \\
\text { to work out people's } \\
\text { intentions. }\end{array}$ & 1 & 1 & & \\
\hline 46. & $\begin{array}{l}\text { New situations } \\
\text { make me anxious. }\end{array}$ & 1 & 1 & & \\
\hline 47. & I enjoy meeting new people. & & & 1 & 1 \\
\hline 48. & I am a good diplomat. & & & 1 & 1 \\
\hline 49. & $\begin{array}{l}\text { I am not very good at } \\
\text { remembering people's } \\
\text { date of birth. }\end{array}$ & & & 1 & 1 \\
\hline 50. & $\begin{array}{l}\text { I find it very } \\
\text { easy to play games } \\
\text { with children that } \\
\text { involve pretending. }\end{array}$ & & & 1 & 1 \\
\hline
\end{tabular}




\section{Appendix B - ADHD Questionnaire}

\section{Adult ADHD Self-Report Scale (ASRS-vI.I) Symptom Checklist}

\begin{tabular}{|c|c|c|c|c|c|c|}
\hline Patient Name & \multicolumn{2}{|c|}{ Today's Date } & & & & \\
\hline \multicolumn{2}{|c|}{$\begin{array}{l}\text { Please answer the questions below, rating yourself on each of the criteria shown using the } \\
\text { scale on the right side of the page. As you answer each question, place an } X \text { in the box that } \\
\text { best describes how you have felt and conducted yourself over the past } 6 \text { months. Please give } \\
\text { this completed checklist to your healthcare professional to discuss during today's } \\
\text { appointment. }\end{array}$} & $\frac{\grave{d}}{\grave{z}}$ & $\frac{\overline{0}}{\stackrel{\frac{0}{\pi}}{\check{\alpha}}}$ & 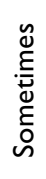 & 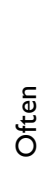 & 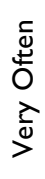 \\
\hline \multicolumn{2}{|c|}{$\begin{array}{l}\text { I. How often do you have trouble wrapping up the final details of a project, } \\
\text { once the challenging parts have been done? }\end{array}$} & & & & & \\
\hline \multicolumn{2}{|c|}{$\begin{array}{l}\text { 2. How often do you have difficulty getting things in order when you have to do } \\
\text { a task that requires organization? }\end{array}$} & & & & & \\
\hline \multicolumn{2}{|c|}{ 3. How often do you have problems remembering appointments or obligations? } & & & & & \\
\hline \multicolumn{2}{|c|}{$\begin{array}{l}\text { 4. When you have a task that requires a lot of thought, how often do you avoid } \\
\text { or delay getting started? }\end{array}$} & & & & & \\
\hline \multicolumn{2}{|c|}{$\begin{array}{l}\text { 5. How often do you fidget or squirm with your hands or feet when you have } \\
\text { to sit down for a long time? }\end{array}$} & & & & & \\
\hline \multicolumn{2}{|c|}{$\begin{array}{l}\text { 6. How often do you feel overly active and compelled to do things, like you } \\
\text { were driven by a motor? }\end{array}$} & & & & & \\
\hline
\end{tabular}

were driven by a motor?

Part A

7. How often do you make careless mistakes when you have to work on a boring or difficult project?

8. How often do you have difficulty keeping your attention when you are doing boring or repetitive work?

9. How often do you have difficulty concentrating on what people say to you, even when they are speaking to you directly?

10. How often do you misplace or have difficulty finding things at home or at work?

II. How often are you distracted by activity or noise around you?

12. How often do you leave your seat in meetings or other situations in which you are expected to remain seated?

13. How often do you feel restless or fidgety?

14. How often do you have difficulty unwinding and relaxing when you have time to yourself?

15. How often do you find yourself talking too much when you are in social situations?

16. When you're in a conversation, how often do you find yourself finishing the sentences of the people you are talking to, before they can finish them themselves?

17. How often do you have difficulty waiting your turn in situations when turn taking is required?

18. How often do you interrupt others when they are busy? 


\section{Appendix C - ROCF Organizational Scoring}

(Hamby et al., 1993)

There are three types of mistakes: configural, secondary, and detail mistakes, defined below. A person's score depends on the number and type of mistakes in the drawing, as follows:

First, count the number of configural mistakes.

- If there are three or more configural mistakes, score 1 for very poor organization. Stop.

1. If there are 0,1 , or 2 configural mistakes, check for a secondary mistake. If present, add to the number of configural mistakes.

- If the total is 3 , then score 1 for very poor organization. Stop.

- If the total is 2 , then score 2 for poor organization. Stop.

- If the total is 1 , then score 3 for fair organization. Stop

2. If there are 0 configural and secondary mistakes, check for detail mistakes.

- If there are 1 or more detail mistakes, score 4 for good organization. Stop.

- If there are 0 detail mistakes, score 5 for excellent organization. Stop.

\section{Configural Mistakes}

The basis configural elements of the Rey-Osterrieth are the outer rectangle and the vertical and horizontal midlines.

1. The following errors are considered configural mistakes (no line can count for more than 1 mistake):

- one side of rectangle/square not drawn when others are completed.

- either of the following drawn in two or more segments constitutes 1 mistake (maximum = 6 mistakes): four sides of rectangle/square or two midlines (i.e., it should only take six lines to complete all of the elements above).

- any details completed before the configural elements are completed, except for the upper left cross (No. 1) of the Rey-Osterrieth. (Because starting in the upper left-hand corner seems to be more related to standard Western writing practice than to poor organization, it is not penalized as heavily.) For example, drawing the right triangle (No. 13) before completing the vertical midline would constitute a configural mistake. Count one mistake for each configural line drawn after the details have been drawn. For example, if the right triangle (No. 13) of the Rey-Osterrieth is begun before both midlines are drawn, score as 2 configural mistakes.

- either midline drawn more than $10 \%$ away from the center (in either direction). That is, the midlines should be in the central $40-60 \%$ of the rectangle/square.

- sides of the rectangle/square not joined at their endpoints, suggesting that the subject does not perceive the rectangle/square. Small draftsmanship errors should not count as a configural mistake. For example, if the right side is placed too far to the right, creating a 6-sided figure, that would count as one configural mistake. Each poorly placed line counts as 1 mistake.

- a configural element is missing (score 1).

\section{Secondary Mistakes}

The diagonals (No. 3) of the Rey-Osterrieth are considered to be secondary elements.

1. Two errors in the reproduction of the secondary elements are considered serious enough to be counted as a secondary mistake, which carries the same weight as configural mistakes. However, the overall construction of these elements can count as a maximum of one mistake. The mistakes are the following:

- the segments do not meet. For the Rey-Osterrieth, all 4 slashes of the diagonal should meet.

- a segment is incomplete (i.e., does not extend all the way across figure).

2. When the elements are drawn as connecting segments, score as a detail mistake. For the Rey-Osterrieth, score as a detail mistake if the patient uses more than two lines to complete the diagonals.

3. Secondary elements can be completed before midlines with no penalty.

\section{Detail Mistakes}

All other elements are considered to be details.

1. Detail mistakes can be made in three ways:

- Unnecessary segmentation. The participant should not use more lines than necessary to complete the element.

- Lines in a standard element, and elements that are near each other, should be drawn consecutively.

- Poor planning that results in the need to redraw an element. For instance, if they must redraw a diagonal line so that it intersects both corners.

2. The following is a partial list of common detail mistakes found in reproductions of the Rey-Osterrieth No. 1 Cross completed before configural elements .No. 6 
- 3 sides of box are not done together (with no break at midline)

- $\mathrm{X}$ is not completed immediately after box is drawn

- $\mathrm{X}$ is drawn as four slashes or two V's (rather than two intersecting lines).

No. 7 Not done immediately after No. 6 .

No. 9 Both sides of triangle not completed together. Vertical side drawn as part of midline and then slanted side completed later.
Nos. 9, 13 The adjacent sides of these two triangles drawn as a single line.

No. 13 Both sides of this triangle not completed together. Nos. 13, 15, 16 Not drawn together.

No. 17 Attachment for cross not completed with rest of cross (e.g., done as part of midline and then finished later).

No. 18

- Slash in box not added when box is first drawn.

- Box, or part of box, drawn as part of the basic configural rectangle.

\section{Appendix D - ROCF Perceptual Scoring}

(Adapted from Osterrieth, 1944)

1. Cross upper left corner, outside of rectangle

2. Large rectangle

3. Diagonal cross

4. Horizontal midline of (2)

5. Vertical midline

6. Small rectangle, within (2) to the left

7. Small segment above (6)

8. Four parallel lines within (2), upper left

9. Triangle above (2), upper right

10. Small vertical line within (2), below (9)

11. Circle with three dots, within (2)

12. Five parallel lines within (2) and crossing (3), lower right

13. Sides of triangle attached to (2) on right

14. Diamond attached to (13)

15. Vertical line within triangle (13), parallel to the right side of (2)

16. Horizontal line within (13), continuing (4) to the right

17. Cross attached to lower center

18. Square attached to (2), lower left
1.

2.

3.

4.

5.

6.

7.

8.

9.

10.

11.

12.

13.

14.

15.

16.

17.

18.

SCORING: Consider each of the 18 units separately. Appraise accuracy of each unit and relative position within the whole of the design. For each unit count as follows:

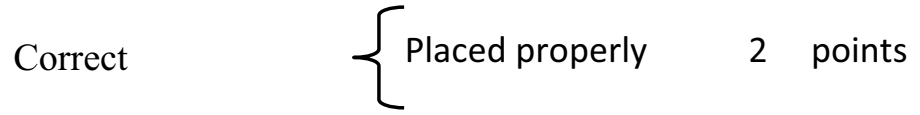

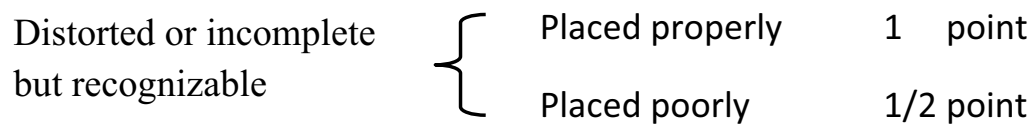
Absent or not recognizable
0 points 
Open Access This article is licensed under a Creative Commons Attribution 4.0 International License, which permits use, sharing, adaptation, distribution and reproduction in any medium or format, as long as you give appropriate credit to the original author(s) and the source, provide a link to the Creative Commons licence, and indicate if changes were made. The images or other third party material in this article are included in the article's Creative Commons licence, unless indicated otherwise in a credit line to the material. If material is not included in the article's Creative Commons licence and your intended use is not permitted by statutory regulation or exceeds the permitted use, you will need to obtain permission directly from the copyright holder. To view a copy of this licence, visit http://creativecommons.org/licenses/by/4.0/.

\section{References}

Agawi TouchMarks (2013) Agawi [apparatus].

Akshoomoff, N. A., \& Stiles, J. (1995a). Developmental trends in visuospatial analysis and planning: I. Copying a complex figure. Neuropsychology, 9(3), 364.

Akshoomoff, N. A., \& Stiles, J. (1995b). Developmental trends in visuospatial analysis and planning: II. Memory for a complex figure. Neuropsychology, 9(3), 378.

American Psychiatric Association. (2015). Diagnostic and statistical manual of mental disorders (5th ed.). : American Psychiatric Publishing.

Anzulewicz A, Sobota K and Delafield-Butt JT (2016) Toward the autism motor signature: Gesture patterns during smart tablet gameplay identify children with autism. Scientific Reports 6 .

Apple Pen (2015) Apple Inc. [apparatus]. https://www.apple.com/ uk/shop/product/MU8F2ZM/A/apple-pencil-2nd-generation. Accessed 3 Oct 2019

Baio, J., Wiggins, L., Christensen, D. L., Maenner, M. J., Daniels, J., Warren, Z., ... \& Durkin, M. S. (2018). Prevalence of autism spectrum disorder among children aged 8 years-autism and developmental disabilities monitoring network, 11 sites, United States, 2014. MMWR Surveillance Summaries, 67(6), 1.

Baron-Cohen, S. (2004). The cognitive neuroscience of autism.

Baron-Cohen, S., Wheelwright, S., Skinner, R., Martin, J., \& Clubley, E. (2001). The autism-spectrum quotient (AQ): Evidence from Asperger syndrome/high-functioning autism, males and females, scientists and mathematicians. Journal of autism and developmental disorders, 31(1), 5-17.

Bishop, J. (2011). The role of augmented E-learning systems for enhancing pro-social behaviour in socially impaired individuals. In Assistive and augmentive communication for the disabled: Intelligent technologies for communication, learning and teaching (pp. 248-272). IGI Global.

Bonett, D. G., \& Wright, T. A. (2000). Sample size requirements for estimating Pearson, Kendall and Spearman correlations. Psychometrika, 65(1), 23-28.

Booth, R. D. L. (2006). Local-global processing and cognitive style in autism spectrum disorders and typical development (Doctoral dissertation, University of London).

Bosco, P., Giuliano, A., Delafield-Butt, J., Muratori, F., Calderoni, S., \& Retico, A. (2019). Brainstem enlargement in preschool children with autism: Results from an intermethod agreement study of segmentation algorithms. Human Brain Mapping, 40(1), 7-19. https://doi.org/10.1002/hbm.24351

Brauer Boone, K. (2000). TEST REVIEW The Boston qualitative scoring system for the Rey-Osterrieth complex figure. Journal of Clinical and Experimental Neuropsychology, 22(3), 430-432.

Broadbent, J., Galic, I., \& Stokes, M. A. (2013). Validation of autism spectrum quotient adult version in an Australian sample. Autism research and treatment, 2013.
Bury, S. M., Jellett, R., Spoor, J. R., \& Hedley, D. (2020). "It Defines Who I Am" or "It's Something I Have": What Language Do [Autistic] Australian Adults [on the Autism Spectrum] Prefer? Journal of Autism and Developmental Disorders, 1-11.

Canham, R. O., Smith, S. L., \& Tyrrell, A. M. (2000). Automated scoring of a neuropsychological test: the Rey Osterrieth complex figure. In Proceedings of the 26th Euromicro Conference. EUROMICRO 2000. Informatics: Inventing the Future (Vol. 2, pp. 406-413). IEEE.

Catanzaro, R. (2005). Performance on the Rey-Osterrieth Complex Figure in high-functioning autism. Indiana University of Pennsylvania.

Cepeda, N. J., Cepeda, M. L., \& Kramer, A. F. (2000). Task switching and attention deficit hyperactivity disorder. Journal of Abnormal Child Psychology, 28(3), 213-226.

Chamberlain, R., Van der Hallen, R., Huygelier, H., Van de Cruys, S., \& Wagemans, J. (2017). Local-global processing bias is not a unitary individual difference in visual processing. Vision Research, 141, 247-257.

Chantiluke, K., Christakou, A., Murphy, C. M., Giampietro, V., Daly, E. M., Ecker, C., ... \& MRC AIMS Consortium. (2014). Disorder-specific functional abnormalities during temporal discounting in youth with Attention Deficit Hyperactivity Disorder (ADHD), Autism and comorbid ADHD and Autism. Psychiatry Research: Neuroimaging, 223(2), 113-120.

Chmiliar, L. (2017). Improving learning outcomes: the iPad and preschool children with disabilities. Frontiers in Psychology, 8, 660.

Cohen, E., \& Kalanthroff, E. (2019). Visuospatial processing bias in ADHD: A potential artifact in the Wechsler Adult Intelligence Scale and the Rorschach Inkblots Test. Psychological Assessment, 31(5), 699.

Concerto, C., Rodolico, A., Avanzato, C., Fusar-Poli, L., Signorelli, M. S., Battaglia, F., \& Aguglia, E. (2021). Autistic Traits and Attention-Deficit Hyperactivity Disorder Symptoms Predict the Severity of Internet Gaming Disorder in an Italian Adult Population. Brain Sciences, 11(6), 774.

Cook JL, Blakemore SJ and Press C (2013) Atypical basic movement kinematics in autism spectrum conditions. Brain 136(Pt 9): 2816-2824.

Cook, J. (2016). From movement kinematics to social cognition: the case of autism. Philosophical Transactions of the Royal Society of London B: Biological Sciences, 371(1693).

Dadalko, O. I., \& Travers, B. G. (2018). Evidence for Brainstem Contributions to Autism Spectrum Disorders. Frontiers in Integrative Neuroscience, 12(47). https://doi.org/10.3389/fnint.2018.00047

Dalbudak, E., \& Evren, C. (2014). The relationship of Internet addiction severity with Attention Deficit Hyperactivity Disorder symptoms in Turkish University students; impact of personality traits, depression and anxiety. Comprehensive psychiatry, 55(3), 497-503.

Davis, J., McKone, E., Zirnsak, M., Moore, T., O'Kearney, R., Apthorp, D., \& Palermo, R. (2017). Social and attention-to-detail subclusters of autistic traits differentially predict looking at eyes and face identity recognition ability. British Journal of Psychology, 108(1), 191-219.

Delafield-Butt, J., Dunbar, P., \& Trevarthen, C. (2021). Disruption to Embodiment in Autism, and Its Repair. In N. Papaneophytou \& U. Das (Eds.), Emerging Programs for Autism Spectrum Disorder: Elsevier Academic Press.

Dibbets, P., Evers, E. A., Hurks, P. P., Bakker, K., \& Jolles, J. (2010). Differential brain activation patterns in adult attention-deficit hyperactivity disorder (ADHD) associated with task switching. Neuropsychology, 24(4), 413.

Ebejer, J. L., Medland, S. E., Van Der Werf, J., Gondro, C., Henders, A. K., Lynskey, M., ... \& Duffy, D. L. (2012). Attention deficit hyperactivity disorder in Australian adults: prevalence, 
persistence, conduct problems and disadvantage. PLoS One, 7(10), e47404.

Eisenberg, D., Nicklett, E. J., Roeder, K., \& Kirz, N. E. (2011). Eating disorder symptoms among college students: Prevalence, persistence, correlates, and treatment-seeking. Journal of American College Health, 59(8), 700-707.

Evren, C., Umut, G., Bozkurt, M., Unal, G. T., Agachanli, R., \& Evren, B. (2016). Psychometric properties of the Turkish version of the Adult ADHD Self-Report Scale (ASRS-v1. 1) in a sample of Inpatients with alcohol use disorder. Dusunen Adam The Journal of Psychiatry and Neurological Sciences, 29(2), 109.

Ferraro, F. R., Hansen, R., \& Deling, L. (2018). Executive Function Index (EFI) performance in nonclinical individuals with high levels of autistic traits. Applied Neuropsychology: Adult, 25(2), 149-154.

Fletcher-Watson, S. (2014). A targeted review of computer-assisted learning for people with autism spectrum disorder: Towards a consistent methodology. Review Journal of Autism and Developmental Disorders, 1(2), 87-100.

Fletcher-Watson, S., \& Happé, F. (2019). Autism: A new introduction to psychological theory and current debate. Routledge.

Fletcher-Watson, S., Petrou, A., Scott-Barrett, J., Dicks, P., Graham, C., O'Hare, A., ... \& McConachie, H. (2016). A trial of an $\mathrm{iPad}^{\mathrm{TM}}$ intervention targeting social communication skills in children with autism. Autism, 20(7), 771-782.

Fournier, K. A., Hass, C. J., Naik, S. K., Lodha, N., \& Cauraugh, J. H. (2010). Motor coordination in autism spectrum disorders: a synthesis and meta-analysis. Journal of autism and developmental disorders, 40(10), 1227-1240.

Frith, U. (1989). Autism and "theory of mind". In Diagnosis and treatment of autism (pp. 33-52). Springer, Boston, MA.

Geurts, H. M., Ridderinkhof, K. R., \& Scholte, H. S. (2013). The relationship between grey-matter and ASD and ADHD traits in typical adults. Journal of Autism and Developmental Disorders, 43(7), 1630-1641.

Groom, M. J., Kochhar, P., Hamilton, A., Liddle, E. B., Simeou, M., \& Hollis, C. (2017). Atypical processing of gaze cues and faces explains comorbidity between autism spectrum disorder (ASD) and attention deficit/hyperactivity disorder (ADHD). Journal of Autism and Developmental Disorders, 47(5), 1496-1509.

Hamby, S. L., Wilkins, J. W., \& Barry, N. S. (1993). Organizational quality on the Rey-Osterrieth and Taylor Complex Figure Tests: A new scoring system. Psychological Assessment, 5(1), 27.

Happé, F. G. (1996). Studying weak central coherence at low levels: children with autism do not succumb to visual illusions. A research note. Journal of Child Psychology and Psychiatry, 37(7), 873-877

Hayward, D. A., Fenerci, C., \& Ristic, J. (2018). An investigation of global-local processing bias in a large sample of typical individuals varying in autism traits. Consciousness and Cognition, 65, 271-279.

Hyun, G. J., Park, J. W., Kim, J. H., Min, K. J., Lee, Y. S., Kim, S. M., \& Han, D. H. (2018). Visuospatial working memory assessment using a digital tablet in adolescents with attention deficit hyperactivity disorder. Computer Methods and Programs in Biomedicine, 157, 137-143.

Kagohara, D. M., Sigafoos, J., Achmadi, D., O’Reilly, M., \& Lancioni, G. (2012). Teaching children with autism spectrum disorders to check the spelling of words. Research in Autism Spectrum Disorders, 6(1), 304-310.

Kalanthroff, E., Naparstek, S., \& Henik, A. (2013). Spatial processing in adults with attention deficit hyperactivity disorder. Neuropsychology, 27(5), 546.

Kandalaft, M. R., Didehbani, N., Krawczyk, D. C., Allen, T. T., \& Chapman, S. B. (2013). Virtual reality social cognition training for young adults with high-functioning autism. Journal of Autism and Developmental Disorders, 43(1), 34-44.

Kessler, R. C., Adler, L., Ames, M., Demler, O., Faraone, S., Hiripi, E. V. A., ... \& Ustun, T. B. (2005). The World Health Organization Adult ADHD Self-Report Scale (ASRS): a short screening scale for use in the general population. Psychological medicine, $35(2), 245-256$.

Kessler, R. C., Adler, L. A., Gruber, M. J., Sarawate, C. A., Spencer, T., \& Van Brunt, D. L. (2007). Validity of the World Health organization adult ADHD self-report scale (ASRS) screener in a representative sample of health plan members. International journal of methods in psychiatric research, 16(2), 52-65.

Kirkorian, H. L., Travers, B. G., Jiang, M. J., Choi, K., Rosengren, K. S., Pavalko, P., \& Tolkin, E. (2020). Drawing across media: A cross-sectional experiment on preschoolers' drawings produced using traditional versus electronic mediums. Developmental psychology, 56(1), 28.

Kuschner, E. S., Bodner, K. E., \& Minshew, N. J. (2009). Local vs. global approaches to reproducing the Rey Osterrieth complex figure by children, adolescents, and adults with high-functioning autism. Autism Research, 2(6), 348-358.

Kushki A, Chau T and Anagnostou E (2011) Handwriting difficulties in children with autism spectrum disorders: a scoping review. Journal of Autism and Developmental Disorders 41(12): 1706-1716.

Lang, K., Roberts, M., Harrison, A., Lopez, C., Goddard, E., Khondoker, M., ... \& Tchanturia, K. (2016). Central coherence in eating disorders: a synthesis of studies using the Rey Osterrieth complex figure test. PloS one, 11(11), e0165467.

Lau, W. Y. P., Gau, S. S. F., Chiu, Y. N., Wu, Y. Y., Chou, W. J., Liu, S. K., \& Chou, M. C. (2013). Psychometric properties of the Chinese version of the Autism Spectrum Quotient (AQ). Research in Developmental Disabilities, 34(1), 294-305.

Luna, B., Doll, S. K., Hegedus, S. J., Minshew, N. J., \& Sweeney, J. A. (2007). Maturation of executive function in autism. Biological psychiatry, 61(4), 474-481.

Lux, E. (2016) studyDraw [Mobile application software].

McKenzie, K., Murray, A. L., Wilkinson, A., Murray, G. C., Metcalfe, D., O'Donnell, M., \& McCarty, K. (2018). The relations between processing style, autistic-like traits, and emotion recognition in individuals with and without Autism Spectrum Disorder. Personality and Individual Differences, 120, 1-6.

Millar, L., McConnachie, A., Minnis, H., Wilson, P., Thompson, L., Anzulewicz, A., . . . Delafield-Butt, J. (2019). Phase 3 diagnostic evaluation of a smart tablet serious game to identify autism in 760 children 3-5 years old in Sweden and the United Kingdom. BMJ Open, 9(7), e026226. https://doi.org/10.1136/bmjop en-2018-026226

Minshew, N. J., \& Goldstein, G. (2001). The pattern of intact and impaired memory functions in autism. The Journal of Child Psychology and Psychiatry and Allied Disciplines, 42(8), 1095-1101.

Mitrushina, M., Boone, K. B., Razani, J., \& D'Elia, L. F. (2005). Handbook of normative data for neuropsychological assessment. Oxford University Press.

Molitor, S. J., Oddo, L. E., Eadeh, H. M., \& Langberg, J. M. (2018). Executive Function Deficits in Adolescents With ADHD: Untangling Possible Sources of Heterogeneity. Journal of Emotional and Behavioral Disorders, 1063426618763125.

Mottron, L. (2001). Université de Montréal Quebec, Canada Jacob A. Burack McGill University. The development of autism: perspectives from theory and research, 119.

Mottron, L., Dawson, M., Soulieres, I., Hubert, B., \& Burack, J. (2006). Enhanced perceptual functioning in autism: an update, and eight principles of autistic perception. Journal of autism and developmental disorders, 36(1), 27-43. 
NHS Digital (2016). Adult Psychiatry Morbidity Study 2014. Chapter 6 retrieved from https://files.digital.nhs.uk/pdf/1/o/adult_psychiatric_study_ch6_web.pdf

Oerlemans, A. M., Droste, K., van Steijn, D. J., de Sonneville, L. M., Buitelaar, J. K., \& Rommelse, N. N. (2013). Co-segregation of social cognition, executive function and local processing style in children with ASD, their siblings and normal controls. Journal of Autism and Developmental Disorders, 43(12), 2764-2778.

Osterrieth, P. A. (1944). The test of copying a complex figure: A contribution to the study of perception and memory. Arch Psychology, 30, 206-356.

Panagiotidi, M., Overton, P. G., \& Stafford, T. (2018). The relationship between ADHD traits and sensory sensitivity in the general population. Comprehensive Psychiatry, 80, 179-185.

Panagiotidi, M., Overton, P. G., \& Stafford, T. (2019). Co-occurrence of ASD and ADHD traits in an adult population. Journal of Attention Disorders, 23(12), 1407-1415.

Plaisted, K., Swettenham, J., \& Rees, L. (1999). Children with autism show local precedence in a divided attention task and global precedence in a selective attention task. The Journal of Child Psychology and Psychiatry and Allied Disciplines, 40(5), 733-742.

Poreh, A. M. (Ed.). (2012). The quantified process approach to neuropsychological assessment. Psychology Press.

Rau, S., Skapek, M. F., Tiplady, K., Seese, S., Burns, A., Armour, A. C., \& Kenworthy, L. (2020). Identifying comorbid ADHD in autism: Attending to the inattentive presentation. Research in Autism Spectrum Disorders, 69, 101468.

Remington, A. M., Swettenham, J. G., \& Lavie, N. (2012). Lightening the load: perceptual load impairs visual detection in typical adults but not in autism. Journal of abnormal psychology, 121(2), 544.

Rey, A. (1941). Psychological examination of traumatic encephalopathy. Archives de psychologie, 28, 286-340.

Riordan, P., Lombardo, T., \& Schulenberg, S. E. (2013). Evaluation of a computer-based administration of the Rey complex figure test. Applied Neuropsychology: Adult, 20(3), 169-178.

Ruzich, E., Allison, C., Smith, P., Watson, P., Auyeung, B., Ring, H., \& Baron-Cohen, S. (2016). Subgrouping siblings of people with autism: Identifying the broader autism phenotype. Autism Research, 9(6), 658-665.

Samsung Galaxy 20 (2020) Samsung [apparatus]. https://www.samsu ng.com/uk/smartphones/galaxy-note20/. Accessed 3 Oct 2019

Schlooz, W. A., Hulstijn, W., van den Broek, P. J., van der Pijll, A. C., Gabreëls, F., van der Gaag, R. J., \& Rotteveel, J. J. (2006). Fragmented visuospatial processing in children with pervasive developmental disorder. Journal of Autism and Developmental Disorders, 36(8), 1025-1037.

Schwieger, D., \& Ladwig, C. (2018). Reaching and retaining the next generation: Adapting to the expectations of Gen $\mathrm{Z}$ in the classroom. Information Systems Education Journal, 16(3), 45.

Woodbury-Smith M. R., Robinson J., Wheelwright S, Baron-Cohen S (2020) Screening adults for Asperger syndrome using the AQ: A preliminary study of its diagnostic validity in clinical practice. Journal of autism and developmental disorders, 35(3), 331-335.

Seidman, L. J., Benedict, K. B., Biederman, J., Bernstein, J. H., Seiverd, K., Milberger, S., ... \& Faraone, S. V. (1995). Performance of children with ADHD on the Rey-Osterrieth complex figure: A pilot neuropsychological study. Journal of Child Psychology and Psychiatry, 36(8), 1459-1473.

Shah, A., \& Frith, U. (1983). An islet of ability in autistic children: A research note. Journal of child Psychology and Psychiatry, 24(4), 613-620.

Shah, A., \& Frith, U. (1993). Why do autistic individuals show superior performance on the block design task?. Journal of Child Psychology and Psychiatry, 34(8), 1351-1364.
Shin, M. S., Park, S. Y., Park, S. R., Seol, S. H., \& Kwon, J. S. (2006). Clinical and empirical applications of the Rey-Osterrieth complex figure test. Nature Protocols, 1(2), 892.

Silverstein, M. J., Faraone, S. V., Leon, T. L., Biederman, J., Spencer, T. J., \& Adler, L. A. (2020). The relationship between executive function deficits and DSM-5-defined ADHD symptoms. Journal of Attention Disorders, 24(1), 41-51.

Simmons, D. R., \& Todorova, G. K. (2018). Local versus global processing in autism: Special section editorial.

Simmons, D. R., Robertson, A. E., McKay, L. S., Toal, E., McAleer, P., \& Pollick, F. E. (2009). Vision in autism spectrum disorders. Vision Research, 49(22), 2705-2739.

Smith, A. D., \& Milne, E. (2017). Dual Coding of object relations: An alternative framework for understanding perceptual processing in autism? Visual Cognition, 25(1-3), 122-132.

Song, Y., \& Hakoda, Y. (2015). Lack of global precedence and globalto-local interference without local processing deficit: A robust finding in children with attention-deficit/hyperactivity disorder under different visual angles of the Navon task. Neuropsychology, 29(6), 888.

Sørensen, L., Sonuga-Barke, E., Eichele, H., van Wageningen, H., Wollschlaeger, D., \& Plessen, K. J. (2017). Suboptimal decision making by children with ADHD in the face of risk: Poor risk adjustment and delay aversion rather than general proneness to taking risks. Neuropsychology, 31(2), 119.

Stern, R. A., Singer, E. A., Duke, L. M., Singer, N. G., Morey, C. E., Daughtrey, E. W., \& Kaplan, E. (1994). The Boston qualitative scoring system for the Rey-Osterrieth complex figure: description and interrater reliability. The Clinical Neuropsychologist, 8(3), 309-322.

Stevenson, J. L., \& Hart, K. R. (2017). Psychometric properties of the autism-spectrum quotient for assessing low and high levels of autistic traits in college students. Journal of Autism and Developmental Disorders, 47(6), 1838-1853.

Taurines, R., Schwenck, C., Westerwald, E., Sachse, M., Siniatchkin, M., \& Freitag, C. (2012). ADHD and autism: differential diagnosis or overlapping traits? A selective review. ADHD Attention Deficit and Hyperactivity Disorders, 4(3), 115-139.

Teitelbaum, P., Teitelbaum, O., Nye, J., Fryman, J., \& Maurer, R. G. (1998). Movement analysis in infancy may be useful for early diagnosis of autism. Proceedings of the National Academy of Sciences, 95(23), 13982-13987.

Torres EB, Brincker M, Isenhower RW, et al. (2013) Autism: The Micro-Movement Perspective. Frontiers in Integrative Neuroscience 7.

Trevarthen C and Delafield-Butt JT (2013) Autism as a developmental disorder in intentional movement and affective engagement. Frontiers in Integrative Neuroscience 7: 49.

Trevarthen, C., \& Delafield-Butt, J. (2019). The Early Embodied Development of ASD, and Its Care. In U. N. Das, N. Papaneophytou \& T. El-Kour (Eds.), Autism 360. : Elsevier.

Tsatsanis, K. D., Noens, I. L., Illmann, C. L., Pauls, D. L., Volkmar, F. R., Schultz, R. T., \& Klin, A. (2011). Managing complexity: Impact of organization and processing style on nonverbal memory in autism spectrum disorders. Journal of Autism and Developmental Disorders, 41(2), 135-147.

Van der Hallen, R., Evers, K., Brewaeys, K., Van den Noortgate, W., \& Wagemans, J. (2015). Global processing takes time: A metaanalysis on local-global visual processing in ASD. Psychological bulletin, 141(3), 549.

Van Eylen, L., Boets, B., Steyaert, J., Wagemans, J., \& Noens, I. (2018). Local and global visual processing in autism spectrum disorders: Influence of task and sample characteristics and relation to symptom severity. Journal of Autism and Developmental Disorders, 48(4), 1359-1381. 
VanVoorhis, C. W., \& Morgan, B. L. (2007). Understanding power and rules of thumb for determining sample sizes. Tutorials in Quantitative Methods for Psychology, 3(2), 43-50.

Vlachou, J., \& Drigas, A. (2017). Mobile technology for students \& adults with Autistic Spectrum Disorders (ASD). International Journal of Interactive Mobile Technologies (iJIM), 11(1), 4-17.

Wagemans, J., Elder, J. H., Kubovy, M., Palmer, S. E., Peterson, M. A., Singh, M., \& von der Heydt, R. (2012). A century of Gestalt psychology in visual perception: I. Perceptual grouping and figure-ground organization. Psychological Bulletin, 138(6), 1172.

Wang, M., \& Reid, D. (2011). Virtual reality in pediatric neurorehabilitation: attention deficit hyperactivity disorder, autism and cerebral palsy. Neuroepidemiology, 36(1), 2-18.

Watanabe, K., Ogino, T., Nakano, K., Hattori, J., Kado, Y., Sanada, S., \& Ohtsuka, Y. (2005). The Rey-Osterrieth Complex Figure as a measure of executive function in childhood. Brain and Development, 27(8), 564-569.
Woodbury-Smith, M. R., Robinson, J., Wheelwright, S., \& BaronCohen, S. (2005).

XCode 12.1 [Computer Software]. (2003). Retrieved from developer. apple.com

XCode Beta [Computer Software]. (2020). Retrieved from developer. apple.com

Claire Morrison is now at the School of Psychology, University of Strathclyde.

Supplementary online materials https://sites.google.com/view/ letsdrawapp/home

Publisher's note Springer Nature remains neutral with regard to jurisdictional claims in published maps and institutional affiliations. 